ARTICLE

\title{
Molecular mechanism of agonism and inverse agonism in ghrelin receptor
}

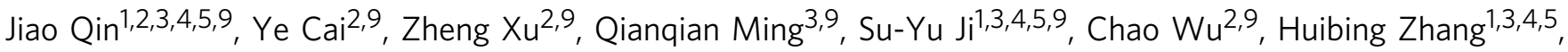

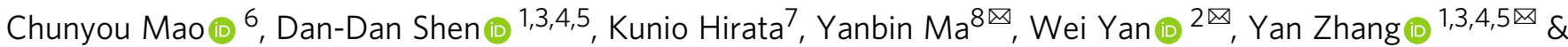 \\ Zhenhua Shao ${ }^{2 凶}$
}

Much effort has been invested in the investigation of the structural basis of $\mathrm{G}$ protein-coupled receptors (GPCRs) activation. Inverse agonists, which can inhibit GPCRs with constitutive activity, are considered useful therapeutic agents, but the molecular mechanism of such ligands remains insufficiently understood. Here, we report a crystal structure of the ghrelin receptor bound to the inverse agonist PF-05190457 and a cryo-electron microscopy structure of the active ghrelin receptor-Go complex bound to the endogenous agonist ghrelin. Our structures reveal a distinct binding mode of the inverse agonist PF-05190457 in the ghrelin receptor, different from the binding mode of agonists and neutral antagonists. Combining the structural comparisons and cellular function assays, we find that a polar network and a notable hydrophobic cluster are required for receptor activation and constitutive activity. Together, our study provides insights into the detailed mechanism of ghrelin receptor binding to agonists and inverse agonists, and paves the way to design specific ligands targeting ghrelin receptors.

\footnotetext{
${ }^{1}$ Department of Biophysics and Department of Pathology of Sir Run Run Shaw Hospital, Zhejiang University School of Medicine, 310058 Hangzhou, China. ${ }^{2}$ Division of Nephrology and Kidney Research Institute, State Key Laboratory of Biotherapy and Cancer Center, West China Hospital, Sichuan University, 610041 Chengdu, Sichuan, China. ${ }^{3}$ Liangzhu Laboratory, Zhejiang University Medical Center, 311121 Hangzhou, China. ${ }^{4}$ MOE Frontier Science Center for Brain Research and Brain-Machine Integration, Zhejiang University School of Medicine, 310058 Hangzhou, Zhejiang, China. ${ }^{5}$ Zheijang Provincial Key Laboratory of Immunity and Inflammatory Diseases, 310058 Hangzhou, China. ${ }^{6}$ Department of General Surgery, Sir Run Run Shaw Hospital, Zhejiang University School of Medicine, 310016 Hangzhou, China. ${ }^{7}$ RIKEN SPring-8 Center, Sayo-cho, Sayo-gun, Hyogo 679-5165, Japan. ${ }^{8}$ Institute of innovation, GeneScience Pharmaceutical Co., Ltd., Shanghai, China. ${ }^{9}$ These authors contributed equally: Jiao Qin, Ye Cai, Zheng Xu, Qanqian Ming, Su-Yu Ji, Chao Wu.

凶email: mayanbin@gensci-china.com; weiyan2018@scu.edu.cn; zhang_yan@zju.edu.cn; zhenhuashao@scu.edu.cn
} 
A $\mathrm{n}$ increasing number of GPCRs have been reported to exhibit high basal or constitutive activity in the absence of extracellular stimuli ${ }^{1-4}$. The spontaneous manner of GPCRs is implicated in human physiological functions and various disorders ${ }^{5}$. As a result, inverse agonists have been discovered as a new ligand category alongside agonists and neutral antagonists $^{6}$. In pharmacology, inverse agonists bind to the orthosteric site of receptors and reduce the constitutive activity of receptors, causing action exactly opposite to agonism and resulting in a paradigm shift in the field of GPCR pharmacology 7,8 . Therefore, understanding the constitutive activity of GPCRs and the mechanism of inverse agonism would contribute to the development of new therapeutic drugs.

The ghrelin receptor ${ }^{9}$, also known as the growth hormone secretagogue receptor (GHSR), belongs to the $\beta$-branch of class A GPCRs and displays constitutive activity ${ }^{10}$ (50\% activity independent of the endogenous ligand ghrelin). The ghrelin receptor exerts a wide range of physiological functions, including appetite regulation, alcohol consumption, adipocyte metabolism, and glucose homeostasis ${ }^{11-14}$, due to its broad distribution and multiple signaling pathways through divergent G-protein coupling or $\beta$-arrestin recruitment ${ }^{15}$. The endogenous agonist ghrelin is a 28 -amino acid peptide secreted primarily by the stomach, and an acylated modification, typically an octanoyl group, of the hydroxyl group of the $\mathrm{Ser}^{+3}$ residue is required for the biological action of ghrelin as the unacylated form of ghrelin does not bind or activate the ghrelin receptor at all ${ }^{16,17}$. In addition, the length of fatty acid modification can also produce diverse activation potency by comparison with the common octanoylated ghrelin in vivo ${ }^{18}$. Previous studies have suggested that inhibition of the ghrelin-ghrelin receptor signaling axis and deacylation of ligands or deletion of receptors could potentially prevent obesity and type 2 diabetes (T2D); thus, blockade of the ghrelin receptor has been proven to be a great therapeutic approach for the treatment of related diseases ${ }^{19-23}$.

Given the constitutive activity of the ghrelin receptor, inverse agonists would be the target of pharmacological agents for maximal efficacy ${ }^{24}$. To date, several reported ligands from different pharmaceutical companies display consistent inverse agonism; ${ }^{25,26}$ however, in some cases, preclinical research is confounding. PF-05190457 is the only reported small-molecule inverse agonist targeting the ghrelin receptor progressing to phase 1 clinical trial for T2D and alcoholism treatment ${ }^{27-29}$. Despite a previous study revealing a bifurcated pocket in the neutral antagonist-bound ghrelin receptor structure ${ }^{30}$, the molecular recognition of PF-05190457 by ghrelin receptors remains unclear, impeding effective drug development.

In this work, we determine the crystal structure of the ghrelin receptor in complex with the inverse agonist PF-05190457 and the cryo-electron microscopy (EM) structure of the active ghrelin receptor bound to endogenous ghrelin coupled to the Go heterotrimer. Our study provides an opportunity to comprehensively understand the distinct conformations of ghrelin receptors bound to different types of ligands. Moreover, our structures reveal a distinct binding mode of inverse agonists with receptors, define cavities for ligand recognition, and decipher the action mechanism of inverse agonists and agonists for ghrelin receptors.

\section{Results}

Overall structures of the ghrelin receptor in complex with inverse agonist and endogenous agonist. The ghrelin receptor is activated by endogenous ghrelin peptide and contains constitutive activity as $\sim 50 \%$ of the maximal activity in the absence of ghrelin peptide $^{31}$. Antagonist compound 21 had no effect on the constitutive activity of the ghrelin receptor ${ }^{30}$, whereas the constitutive activity of the ghrelin receptor was significantly reduced upon the addition of the inverse agonist PF-05190457 (Fig. 1a).

To describe the molecular mechanism of the ghrelin receptor in binding with PF-05190457, the initial construct of the ghrelin receptor was truncated by eliminating the first $\mathrm{N}$-terminal 34 amino acid residues and the C-terminus after residue 342 . To facilitate crystallization, a thermostabilized apocytochrome bRIL was fused to the third intracellular loop (ICL3). Furthermore, mutations of $\mathrm{T} 130^{3.39} \mathrm{~K}$ and $\mathrm{N} 188^{\mathrm{ECL} 2} \mathrm{Q}$ were introduced to improve the thermostability and homogeneity of the receptor as described in our previous study ${ }^{32}$ (Supplementary Fig. 1a-d) This construct was crystallized in a complex with PF-05190457 and determined at a resolution of $2.94 \AA$ (Fig. 1b). In the resolved crystal structure, the PF-05190457-bound ghrelin receptor is packed in a $\mathrm{P} 2{ }_{1}$ monoclinic lattice with two complex molecules per asymmetric unit (Supplementary Fig. 1e). The two receptor molecules display high identity with an RMSD value of $0.3 \AA$ (root-mean-square deviation of $\mathrm{C}_{\alpha}$ ) (Supplementary Fig. 1f).

In addition, we determined the ghrelin-bound ghrelin receptor-Go complex using a single-particle cryo-EM technique. The full-length of wild-type human ghrelin receptor, the thermostabilized miniGaol ${ }^{33}, \mathrm{G} \beta 1$, and $\mathrm{G} \gamma 2$ were co-expressed in insect cells. We used the NanoBiT tethering strategy ${ }^{34}$ to
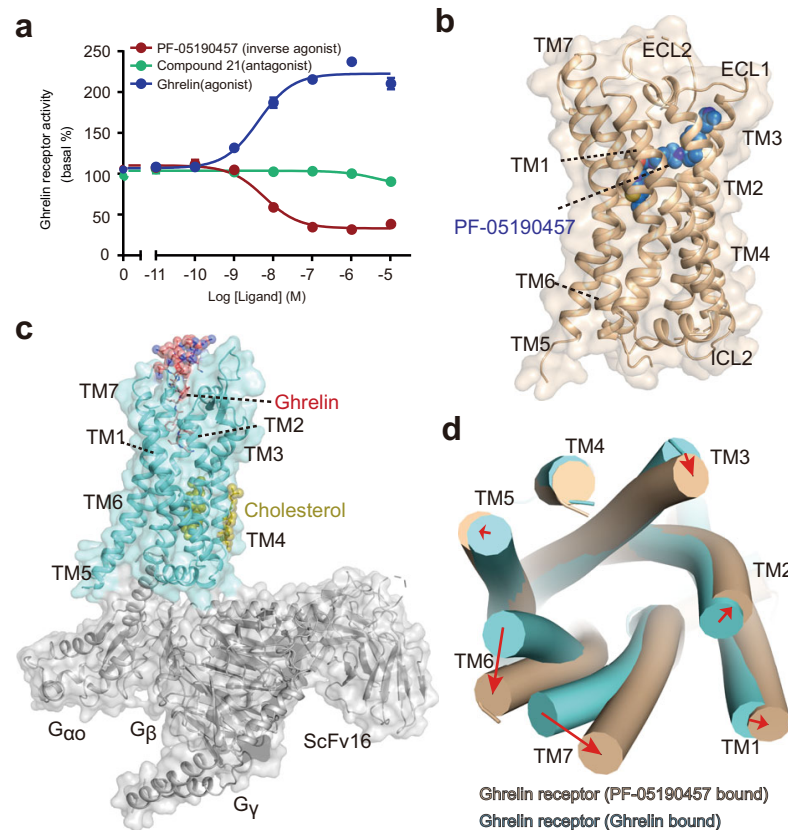

Ghrelln receptor (Ghrellin bound)

Fig. 1 Overall structures of ghrelin receptors bound to inverse agonist and agonist. a Dose-dependent responses of endogenous agonist ghrelin, inverse agonist PF-05190457 and antagonist compound 21 containing $10 \mathrm{nM}$ ghrelin peptide at wild-type ghrelin receptor measured by cellular IP1 accumulation assays. The ghrelin peptide represents high activation potency as a full agonist, and PF-05190457 functions as an inverse agonist to significantly reduce basal activity (dotted line). Data represent the mean \pm SEM from $n=3$ biologically independent experiments performed in triplicate. $\mathbf{b} V$ iew from within the plane of the membrane. The inverse agonist-bound ghrelin receptor is represented as a wheat cartoon, and PF05190457 is shown as a marine blue sphere. Cryo-EM structure of the agonist ghrelin-bound ghrelin receptor-Goo1-scFv16 complex. c Ghrelin peptides and receptors are shown as deep salmon spheres and aquamarine cartoons, respectively. The Go heterotrimer and scFv16 are shown in the gray cartoon. d View from the extracellular side of the membrane. The structural comparison of inverse agonist-bound (wheat) with agonistbound structures (aquamarine) reveals that notable outward movements occur in the extracellular ends of TM domains. 
stabilize the complex, in which the C-terminus of ghrelin receptor was attached to $\operatorname{LgBiT}$ subunit and $\mathrm{G} \beta 1$ was fused with a C-terminal HiBiT subunit. An antibody fragment, scFv16, was also added. The final cryo-EM map has a nominal resolution of $2.8 \AA$ after refinement, and a clear density map allows us to build the ghrelin peptide, receptor, Go, G $\beta, G \gamma$, and scFv16 (Fig. 1c and Supplementary Figs. 2 and 3). The ghrelin receptor-Go complex displays similar conformations compared with previously solved activated GPCR-Go structures (Supplementary Fig. 4), suggesting that the ghrelin receptor bound to ghrelin was in an activated state.

Compared with the active structure, the extracellular portion of PF-05190457-bound ghrelin receptors, especially TM6 and TM7, displayed notable outward movement, enlarging the orthosteric pocket of the receptor (Fig. 1d). In addition, distinct conformational changes were also found in the cytoplasmic region of the receptor, in which TM6 swing inwards by $\sim 10 \AA$ to hinder the coupling of $\mathrm{G}$ proteins (Supplementary Fig. $5 \mathrm{a}-\mathrm{c}$ ).

Inverse agonist binding pocket of ghrelin receptor. The compound PF-05190457 was synthesized from a spiro-azetidinopiperidine analog to improve the selectivity and inverse agonism $^{27}$. Like most inverse agonists, the PF-05190457-bound ghrelin receptor complex reflects an inactive state conformation that differs from the complex bound with agonists or antagonists $^{35-37}$ (PDB ID: 6CM4, 6K1Q, 5U09). Strikingly, unambiguous electron density at the orthosteric pocket placed PF-05190457 at an unusual site toward TM2, TM3, and TM6 (Fig. 2a), contrasting with the site occupied by the antagonist in the ghrelin receptor ${ }^{30}$ (Fig. 2b). The antagonist compound 21bound ghrelin receptor complex structure demonstrates a bifurcated ligand-binding pocket separated by a salt bridge between $\mathrm{E} 124^{3.33}$ and R2836.55, which is referred to as cavity I and $\mathrm{II}^{30}$ (Fig. 2b). Whereas PF-05190457 adopts an extended conformation (Fig. 2c-g), the arm-1 ((6-methylpyrimidin-4-yl)-2,3-dihydro-1 H-inden-1-yl moiety) (Fig. 2c) of the ligand projects into the cleft between TM2 and TM3 and is covered by ECL1 and ECL2 regions, making van der Waals contacts and hydrophobic interactions with $\mathrm{R} 102^{2.63}$, Q120 $0^{3.29}$, and F1193.28 as well as disulfide-bound $\mathrm{C} 116^{3.25}$ and C198 ${ }^{\mathrm{ECL} 2}$ (Fig. 2d). The cleft between TM2 and TM3 accommodates arm-1 of PF-05190457 is defined as cavity III. Two residues, F1193.28 A and Q120 ${ }^{3.29} \mathrm{~A}$ substitution, were found to be essential for the inverse agonism potency of PF-05190457 (Supplementary Figs. 6a and 7a, b).

The diazaspiro core (2,7-diazaspiro [3,5] nonan-7-yl moiety) of PF-05190457 is adopted in cavity I, forming direct interactions with D992.60 and S308 7.38 by hydrogen bonding (Fig. 2c, e). Alanine replacement with D99 2.60 significantly reduced the potency of inverse agonism induced by PF-05190457 (Fig. 2g and Supplementary Fig. 7a, b), indicating that D992.60 may be a key facet for inverse agonist recognition or receptor activation, which is consistent with a previous report that the diazaspiro core moiety was typically required for inverse agonism ${ }^{27,38}$. In addition, mutation of $S 308^{7.38}$ to alanine decreased the inverse agonism potency of PF-05190457, which may affect the recognition of the ligand and reduce the stability of the inactive conformation (Fig. $2 \mathrm{~g}$ and Supplementary Fig. 7a, b). Both the $\mathrm{D} 99^{2.60} \mathrm{~A}$ and $\mathrm{S} 308^{7.38} \mathrm{~A}$ mutants retained the expression level of the wild-type ghrelin receptor by normalization (Supplementary Figs. 6a and $7 \mathrm{~b})$.

Arm-2 (2-methylimidazo moiety) penetrates deeply into the helical core of the receptor, and it packs against the side chains of residues F2796.51, W2766.48, and F3127.42 in TM6 and TM7, opening another hydrophobic pocket defined as cavity IV (Fig. 2f). In addition, arm- 2 is also observed to form hydrogen bonds with residues W276 6.48 and $\mathrm{S} 308^{7.38}$ (Fig. 2f). Disrupting the hydrophobic pocket by replacing F2796.51, W276 6.48 , and F312 7.42 with alanine significantly reduced the inverse agonistic activity (Fig. 2g). Moreover, these mutations also impaired the potency of the agonist ghrelin peptide and antagonist compound 21 (Fig. 2g and Supplementary Fig. 6b), indicating that aromatic residues are essential for the activation transition of the ghrelin receptor.

Structural comparison of PF-05190457-bound with compound 21-bound ghrelin receptor complex reveals a notable difference. The salt bridge between E124 3.33 and R2836.55 formed in the antagonist receptor structure is disrupted upon receptor binding with PF-05190457 (Fig. 2h). Residue R2836.55 swings away from E124 3.33 , leading to the disappearance of the boundary between cavity I and cavity II. In contrast to the obvious change in the extracellular portion, the cytoplasmic ends of TM5 and TM6 in the PF-05190457-bound structure display conformations similar to those of the inactive ghrelin receptor, suggesting that the inverse agonist stabilizes the receptor in an inactive conformation (Supplementary Fig. 5d-f).

Agonist binding pocket of ghrelin receptor. Distinct from the small-molecule inverse agonist binding mode, the endogenous ghrelin peptide is well folded and stably anchored into its binding site through an extensive network of contacts with the receptor. The synthetic ghrelin peptide contains 28 residues, and an octanoyl modification was introduced at the side chain of $\mathrm{Ser}^{+3}$ (the superscript $+\mathrm{n}$ indicates the amino acid position of ghrelin peptide). The first sixteen residues are clear in our density map (Supplementary Fig. 3). The N-terminal portion of ghrelin from $\mathrm{Gly}^{+1}$ to $\mathrm{Pro}^{+7}$ penetrates into the conserved orthosteric pocket (Fig. 3a), where Gly ${ }^{+1}$ and Ser $^{+2}$ fill cavity I and are stabilized by a hydrogen-bound network formed by S1233.32, N305.35, and R283 $6.55^{5}$ in the ghrelin receptor (Fig. 3b). Meanwhile, R283 ${ }^{6.55}$ is stabilized via a salt bridge with E124.33 and a hydrogen bond with $\mathrm{S} 217^{5.43}$ (Fig. 3b).

Notably, the interaction between $\mathrm{S} 217^{5.43}$ and R2836.55 was found only in the agonist-bound structure and not in the antagonist-bound structure (Supplementary Fig. 8a). These observations, particularly for the rotamer change of $\mathrm{R} 283^{6.55}$, reveal that rearrangement of the residues in the polar network appears to tether those key residues on TM3, TM5, TM6, and TM7, contracting the agonist binding pocket of the receptor. In agreement with our structural comparison, alanine substitution of residues $\mathrm{E} 124^{3.33}$ and $\mathrm{N} 305^{7.35}$ in the receptor remarkably reduced the activation potency induced by the ghrelin peptide, while alanine substitution of residue R2836.55 almost abolished the efficacy (Fig. 3c), suggesting that the polar interactions of E124 $4^{3.33}, \mathrm{R} 283^{6.55}$, S217 5.43 , and $\mathrm{N} 305^{7.35}$ in the receptor and Gly ${ }^{+1}$ and $\mathrm{Ser}^{+2}$ in the ghrelin peptide play significant roles in receptor activation. In accordance with previously published Gq-coupled ghrelin receptors in complex with ghrelin structure ${ }^{39}, \mathrm{Gly}^{+1}$ and $\mathrm{Ser}^{+2}$ in ghrelin are engaged in similar contacts with receptors (Supplementary Fig. 8b).

In the GPCR activation transition, rearrangement of the polar network is required for conformational propagation. The activation process of $\beta 2 \mathrm{AR}$, for example, is the bestcharacterized member of the GPCR family; residues $\mathrm{D}^{3.32}, \mathrm{~S}^{5.42}$, and $S^{5.46}$ from TM3 and TM5 constitute a key polar motif for distinguishing different types of ligands and trigger signaling pathways (PDB: $4 \mathrm{LDO})^{40}$, and a polar interaction manner was also found in the D1 receptor (PDB: $7 \mathrm{CKZ})^{41}$ (Supplementary Fig. $8 \mathrm{~d}-\mathrm{f}$ ). Despite the divergent nature of the endogenous ligand between the ghrelin receptor and aminergic receptors, the ghrelin receptor appears to have a similar activation process as aminergic receptors. 
a

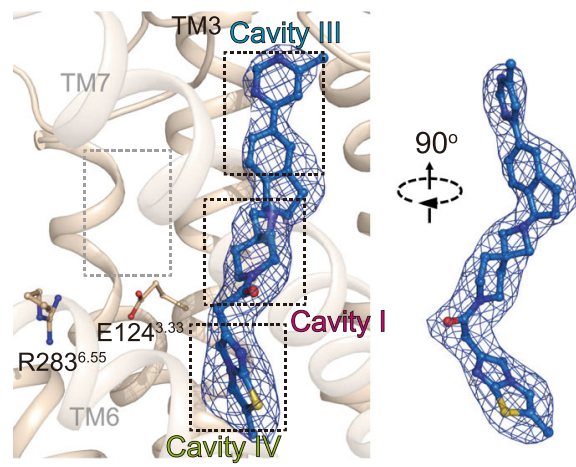

Ghrelin receptor - PF-05190457

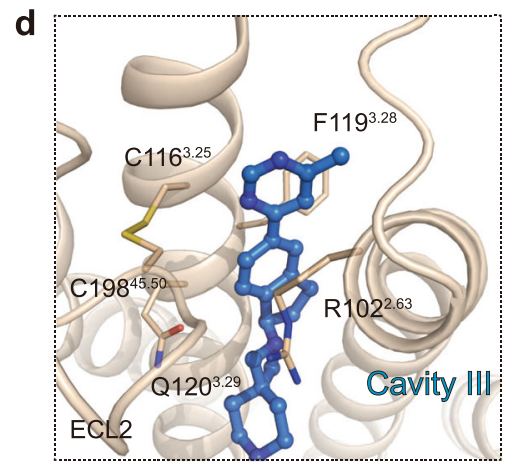

f

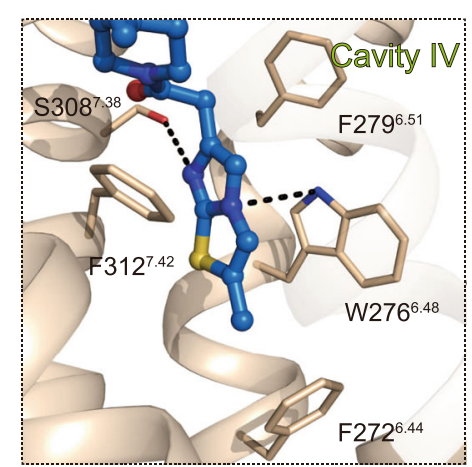

b

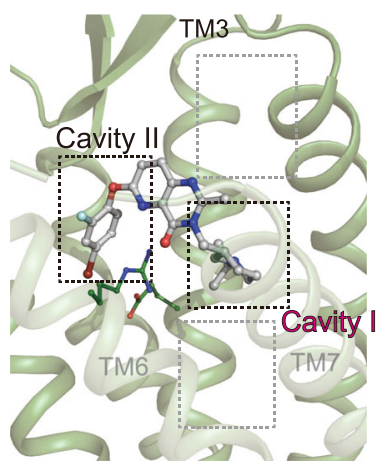

Ghrelin receptor - Antagonist

C<smiles>Cc1cc(-c2ccc3c(c2)CC[C@H]3C)ncn1</smiles>

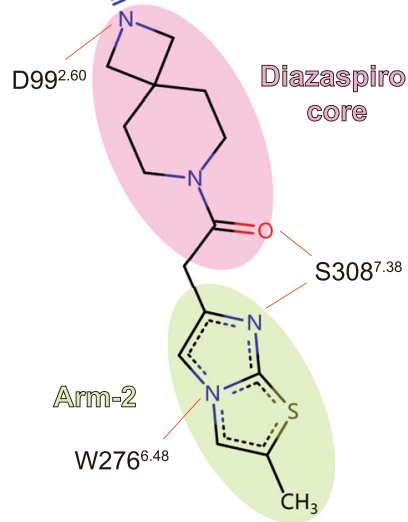

$\mathbf{h}$
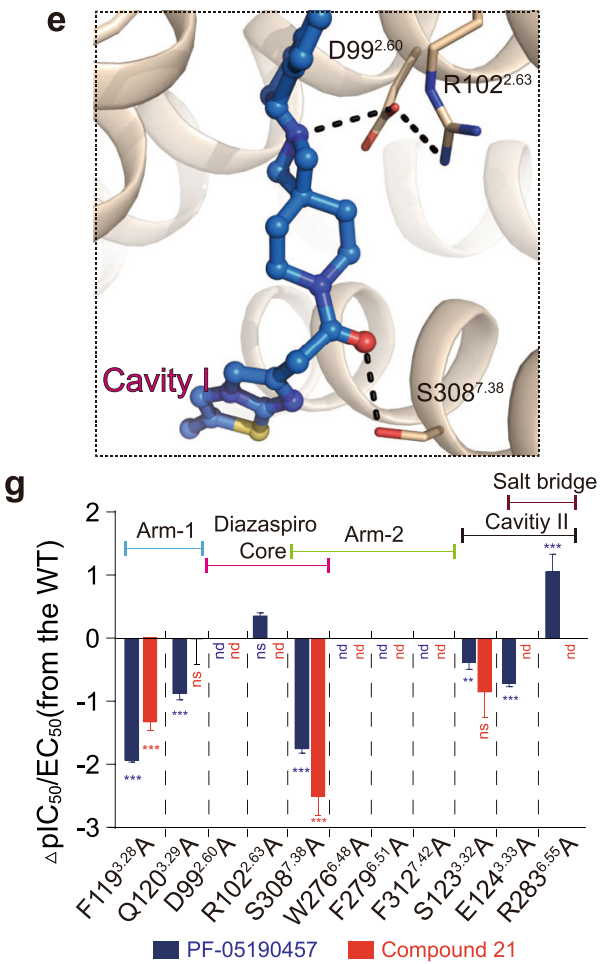

(1)

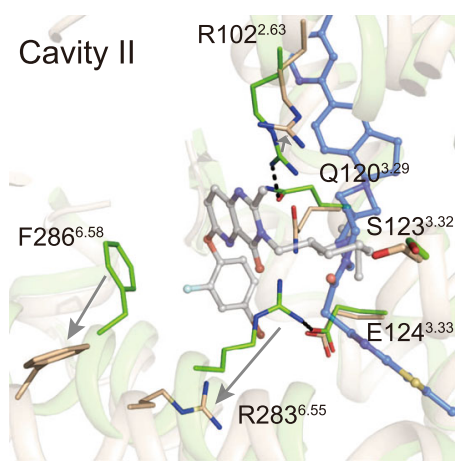

Fig. 2 The binding mode of PF-05190457 with the ghrelin receptor. a The detailed binding mode of PF-05190457 in the orthosteric pocket of the ghrelin receptor. The $|\mathrm{Fo}|-|\mathrm{Fc}|$ omit map (contoured at $3.0 \sigma$ ) for PF-05190457 (shown as marine blue sticks). In particular, the herein described cavities of the ghrelin receptor named cavity III and cavity IV. b The structure of the neutral antagonist (gray stick)-bound ghrelin receptor (forest cartoon) (PDB: 6KO5) reveals a bifurcated ligand-binding pocket, which is referred to as cavities I and II. c Two-dimensional structures of the inverse agonist PF-05190457 and the groups of ligands are termed the diazaspiro core, arm-1 and arm-2. The diazaspiro core is shown in pink, arm-1 is sky blue, and arm-2 is light green. The red solid lines indicate hydrogen bonds involved in interactions with the side chains of key residues. $\mathbf{d}$-f Key residues of the ghrelin receptor (wheat sticks) involved in ligand binding in cavity III (d), cavity I (e), and cavity IV (f). The binding pocket is highly hydrophobic, and the particular polar network is shown as black dotted lines. $\mathbf{g}$ IP1 accumulation induced by the inverse agonist PF-05190457 and antagonist compound 21. Bars represent the difference in the calculated potency $\left(\mathrm{plC}_{50}\right.$ ) of the inverse agonist for mutations relative to the WT ghrelin receptor. Data are colored according to extent of effect. nd not detected, ${ }^{\star \star} P<0.01$, ${ }^{\star \star \star} P P<0.001$ (one-way analysis of variance (ANOVA) followed by Dunnett's test, compared with the response of WT, $P<0.001$, $P<0.001, P<0.001, P>0.999$, nd, nd, $P=0.05$, nd, $P<0.001, P<0.001$, nd, nd, nd, nd, nd, nd, $P<0.01, P=0.264, P<0.001$, nd, $P<0.001$, nd from left to right). Data represent the mean \pm SEM from $n=3$ biologically independent experiments performed in triplicate. See also Supplementary Figs. 6 and 7 . h Structural superimposition of inverse agonist-bound with neutral antagonist-bound structures shows significant displacements of the critical residues in the orthosteric pocket. The salt bridges between E1243.33 and R2836.55 as well as between R102 2.63 and Q1203.29, are broken upon PF-05190457 binding.

Although residue $\mathrm{Ser}^{+3}$ of ghrelin could be modified with different lengths of acylated modification ${ }^{42,43}$, octanoyl modification is optimal for its activation and biological function ${ }^{16,17}$. The octanoyl group in our structure shows a well-defined density through the cryo-EM map and is observed to bind to hydrophobic cavity II, which comprises residues I178 4.60 , $\mathrm{L} 181^{4.63}, \mathrm{~L} 210^{5.36}, \mathrm{M} 213^{5.39}, \mathrm{~V} 214^{5.40}$, and $\mathrm{F} 286^{6.58}$ from TM4, TM5, and TM6 (Fig. 3d). As seen from the cut view of cavity II, the octanoyl group definitely fits well in the pocket rather than the other type of fatty acid modification (Supplementary Fig. 8g, h).

The importance of these hydrophobic contacts was validated by single-mutation and cell-based function assays, and our results showed that mutations of $1178^{4.60} \mathrm{~A}, \mathrm{~L} 210^{5.36} \mathrm{~A}$, and $\mathrm{F} 286^{6.58} \mathrm{~A}$ decreased the receptor activation induced by ghrelin (Fig. 3d). This finding indicates the critical role of the octanoylation of 

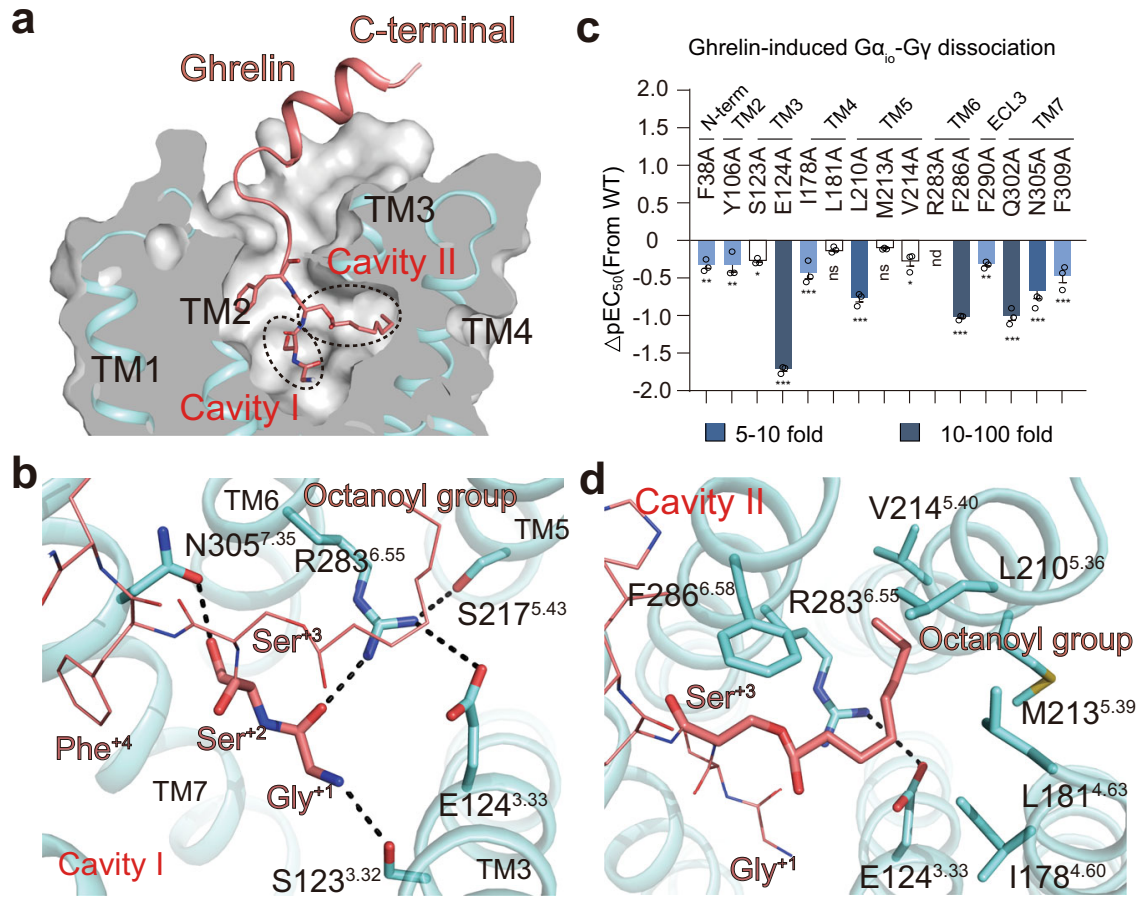

Fig. 3 Recognition of ghrelin by ghrelin receptor. a The cutaway surface of the ghrelin receptor bound to the ghrelin structure reveals that ghrelin occupies the bifurcated ligand-binding pocket with the residues Gly ${ }^{+1}$ and Ser ${ }^{+2}$ filling up cavity I and its octanoyl group of Ser +3 inserting into cavity II. b Detailed polar interaction of both residues $\mathrm{Gly}^{+1}$ and $\mathrm{Ser}^{+2}$ (aquamarine sticks) with the key residues from cavity I. c Ghrelin-induced Gao1-G $\gamma$ dissociation assay. Bars represent differences in calculated potency $\left(\mathrm{pEC}_{50}\right)$ of ghrelin for mutations relative to the WT ghrelin receptor. Data are colored according to the extent of the effect. ${ }^{\star} P<0.1,{ }^{\star \star} P<0.01$ and ${ }^{\star \star \star} P<0.001$. ns no significant difference, nd not detected. All data were analyzed by one-way analysis of variance (ANOVA) followed by Dunnett's multiple comparison test, compared with the response of WT $(P=0.002, P=0.002, P=0.015$, $P<0.001, P<0.001, P=0.732, P<0.001, P=0.843, P=0.012, P<0.001, P=0.003, P<0.001, P<0.001$ and $P<0.001$ from left to right). Data represent the mean \pm SEM from $n=3$ biologically independent experiments performed in triplicate. See also Supplementary Figs. 6 and 7. d Detailed interaction of the octanoyl group of $\mathrm{Ser}^{+3}$ with the key residues from cavity II and salt bridges between E1243.33 and R2836.55 are clearly observed in the ghrelin-bound structure.

ghrelin in receptor activation as well as the downstream signaling cascade.

Moreover, the contacts between the receptor and ghrelin peptide at the extracellular portion of TM bundles, accompanied by extensive interaction of ECL regions with the C-terminal helix of ghrelin, further stabilize the binding of the receptor with ghrelin (Supplementary Fig. 9a, b). The F38 ${ }^{\mathrm{N}-t e r m}, \mathrm{Y}_{106}{ }^{2.67}$, F290 ${ }^{\text {ECL3 }}$, Q302 7.32 , and F3097.39 form hydrophobic and polar interactions with the residues $\mathrm{Phe}^{+4}$ and $\mathrm{Leu}^{+5}$ of ghrelin. Mutation of those residues, especially Q302 7.32 and F3097.39 impaired ghrelin-induced G-protein signaling (Fig. 3d).

Mechanism of ghrelin-induced activation. The comparison of the ghrelin-bound complex structure with the neutral antagonistbound structure shows that the TM bundles at the extracellular portion are similar, except that the helix end of TM7 is tilted outward by $\sim 5.5 \AA$ (Fig. $4 \mathrm{a}$ ). Moreover, the conformation of the intracellular end of TM bundles is widely changed. The ends of TM3, TM5, TM6, and TM7 shifted by $~ 2.8,2.3,13.4$, and $2.9 \AA$ (referring to the $\mathrm{Ca}$ of each $\mathrm{TM}$ terminal residue: $\mathrm{C} 146^{3.55}$, $\mathrm{L} 239^{5.65}$, L253 ${ }^{6.25}$, and $\mathrm{L} 322^{7.52}$ ), respectively (Fig. $4 \mathrm{~b}$ ). The obvious rearrangement of TM6 as well as the movement of other ends of TMs, which was likewise observed in the Gq-coupled ghrelin receptor structure, make a suitable binding cavity available for the G protein (Fig. 4b and Supplementary Fig. 9c).

The N-terminal part in ghrelin stretches on top of an aromatic cascade formed by W276 ${ }^{6.48}, \mathrm{~F} 279^{6.51}$, and F312 7.42 , which is referred to as the WFF cluster hereafter. In the neutral antagonistbound structure, F312 7.42 was positioned closely and tightly packed against F2796.51 and W2766.48. In the ghrelin-bound structure, the side chains of F3127.42, W276 6.48 , and F2796.51 display significant rotation and displacement toward the extracellular end (Fig. 4c).

R283 6.55 is situated above F2796.51 and connects the WFF cluster with the polar network associated with the binding of ghrelin. Compared with the neutral antagonist-bound structure, the side chain of R283 6.55 has an obvious swing toward TM5 in the ghrelin-bound structure and appears to trigger local rearrangement of the TM6 bundle. Residues F2796.51 and W276 6.48 shift significantly along with the outward movement of TM6. Notably, F2796.51 interacts directly with ghrelin and involves cation- $\pi$ interactions with $\mathrm{R} 283^{6.55}$, which also contributes to the movement of F2796.51. The swing of W2766.48 subsequently switches F2726.44 (Fig. 4d), resulting in a cascade of relocations of highly conserved activation motifs such as the $\mathrm{P}^{5.50} \mathrm{I}(\mathrm{V})^{3.40}-\mathrm{F}^{6.44}$ motif, $\mathrm{D}(\mathrm{E})^{3.49}-\mathrm{R}^{3.50}-\mathrm{Y}^{3.51}$ motif, and $\mathrm{N}^{7.49}$. $\mathrm{P}^{7.50}-\mathrm{xx}-\mathrm{Y}^{7.53}$ motif (Supplementary Fig. 9d-f), leading to the change in TM6 on the intracellular side and enabling the receptor to bind to the $G$ protein. Mutagenesis and functional analyses further verify our hypothesis. Site-directed mutants $\mathrm{E} 124^{3.33} \mathrm{~A}$, $\mathrm{R} 283^{6.55} \mathrm{~A}, \mathrm{~F} 279^{6.51} \mathrm{~A}$, or W276 $6^{6.48} \mathrm{~A}$ almost abolished the activity of the ghrelin receptor, while $\mathrm{F} 312^{7.42} \mathrm{~A}$ impaired ghrelin-induced G-protein signaling, implying the critical role of the polar network and the WFF cluster in activation (Fig. 4e).

Aromatic amino acids also contribute to the activation of several other peptide receptors. For instance, W32 ${ }^{6.48}, \mathrm{~F} 358^{7.42}$, and Y $324^{6.51}$ in NTSR1, which belongs to the ghrelin receptor family (PDB ID: 4XEE), display a similar significance in 
a

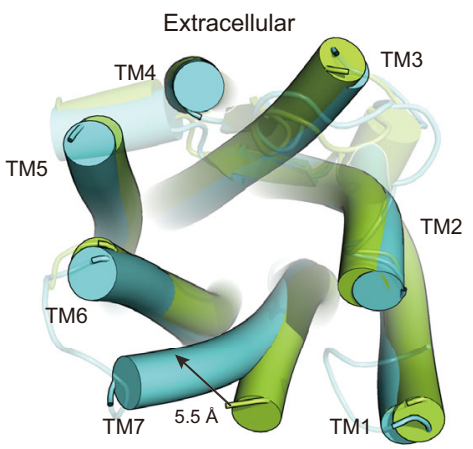

C.

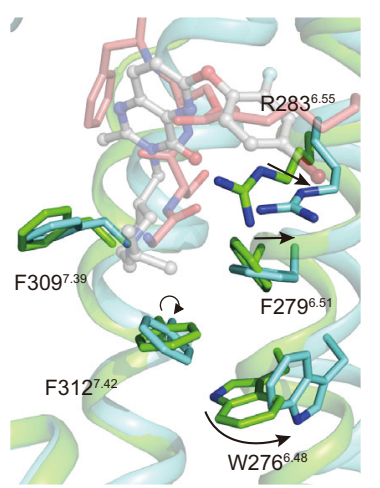

d

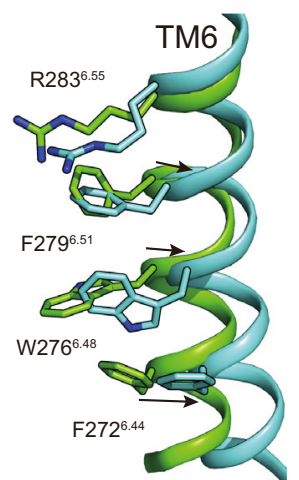

b

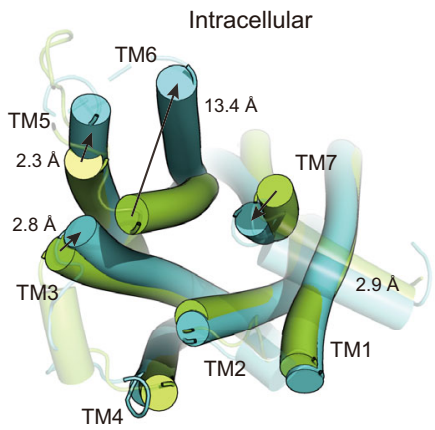

e

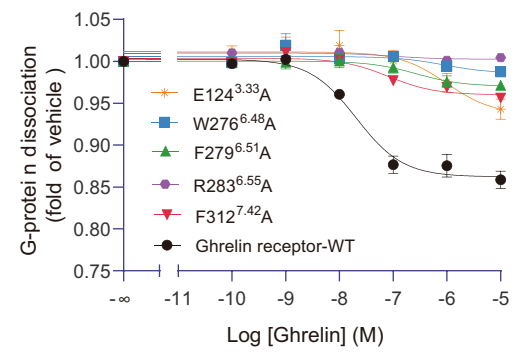

Ghrelin receptor = Ghrelin

Ghrelin receptor - neutral antagonist

Fig. 4 Mechanism of ghrelin action on ghrelin receptor. a, b Structural comparison of agonist-bound with neutral antagonist-bound structures (PDB: 6KO5) reveals remarkable displacements in the extracellular side (a) and intracellular side (b), resulting in contracting of the orthosteric binding pocket in the extracellular side as well as making a cavity to couple $\mathrm{G}$ protein in the intracellular side. c Superposition of ghrelin-bound (aquamarine cartoon) and neutral antagonist-bound (forest cartoon) structures shows that the WFF cluster exhibits obvious conformational displacements upon ghrelin binding. d The rearrangement of local residues in the backbone of TM6 between ghrelin-bound (aquamarine cartoon) and neutral antagonist-bound (forest cartoon) structures (PDB: 6KO5) shows the cascade changes of residues R2836.55, F272 ${ }^{6.44}$, and the WFF cluster. e Mutations of W2766.48, F2796.51, and $\mathrm{F} 312^{7.42}$ in the ghrelin receptor decreased the activation potency induced by ghrelin. Data represent the mean \pm SEM from $n=3$ biologically independent experiments performed in triplicate. See also Supplementary Figs. 6 and 7.

activation $^{44}$. W86 $2.60, \mathrm{Y}^{3} 108^{3.32}$ and $\mathrm{Y} 251^{6.51}$ of CCR5 ${ }^{45}$ (PDB ID: $7 \mathrm{~F} 1 \mathrm{R})$ and $\mathrm{W}^{6.48}-\mathrm{F}^{6.51}-\mathrm{G}^{7.42}$ of $5-\mathrm{HT} 2 \mathrm{aR} / 2 \mathrm{cR}^{46,47}$ (PDB ID: $6 \mathrm{WH} 4,6 \mathrm{BQH})$ were also involved in constitutive activation. The aromatic cascade is also intimately connected with activation in lipid receptors, such as the $S 1 P_{1}$ receptor ${ }^{48}$ and the $C_{1}$ receptor ${ }^{49}$. Collectively, our work demonstrates a possible activation mechanism associated with aromatic clusters for GPCRs.

Mechanism of inverse agonist action on the ghrelin receptor. The comparison of the inverse agonist-bound ghrelin receptor structure with agonist-bound and neutral antagonist-bound structures enabled us to visualize the plasticity of the TM domain, reflecting different conformational states of the ghrelin receptor (Supplementary Fig. 5). As observed, the inverse agonist PF-05190457 appears to stabilize the receptor in an inactive conformation with respect to the binding of the $G$ protein (Supplementary Fig. 5b, e). PF-05190457 has distinct chemical moieties with neutral antagonist compound 21, displaying extensive contacts with orthosteric sites. Arm-2 (2-methylimidazo moiety) of PF-05190457 penetrates deeply into the helical bundle and is sandwiched by the WFF cluster (Fig. 5a). As the basal activity of the ghrelin receptor is blocked significantly by inverse agonists, the WFF cluster from the hydrophobic pocket exhibits significant displacement relative to that in agonist-bound and antagonist-bound receptor structures (Fig. 5b). Notably, the side chain of W276 6.48 rotates nearly $180^{\circ}$ and tilts $\sim 3 \AA$ toward the extracellular end, and together with the side chain of F2796.51, it also displays upward movement, therefore pushing out the extracellular end of TM6 and enlarging the ligand-binding pocket, subsequently impeding the formation of a salt bridge by dragging R283 6.55 away from $\mathrm{E} 124^{3.33}$ (Fig. 5c). These conformational changes also impair the rearrangement of the PIF motif, ERY motif, and NPxxY motif (Supplementary Fig. 9d-f), which is distinct from the conformational changes in agonistbound and antagonist-bound structures.

To investigate the molecular basis for the aromatic cluster in binding with inverse agonist, we performed cell-based function assays and designed a series of mutations of $\mathrm{W} 276^{6.48} \mathrm{~A}, \mathrm{~F} 279^{6.51} \mathrm{~A}$, and $\mathrm{F} 312^{7.42} \mathrm{~A}$ as well as R283 ${ }^{6.55} \mathrm{~A}$ (Figs. $4 \mathrm{c}$ and $5 \mathrm{e}$ ). All four single mutations showed not only decreased receptor activation but also impaired inverse agonism, which is consistent with previous reports that the mutation of aromatic residues from TM6 and TM7 impaired the constitutive activity of the ghrelin receptor ${ }^{31}$.

In addition to the change in the hydrophobic portion in the orthosteric site, the rearrangement of the polar network occurs as inverse agonist binding. Through structural comparison with ghrelin-bound, the PF-05190457-bound complex structure shows breaking of the salt bridge between R283 6.55 and E1243.33, breaking of the weak polar interaction between $\mathrm{R} 102^{2.63}$ and Q1203.29, and newly established polar interactions between the inverse agonist and residues $\mathrm{S} 308^{7.38}$ and $\mathrm{D} 99^{2.60}$ (Fig. 5d). Notably, E124 $13.33 \mathrm{~A}$ and R283 ${ }^{6.55} \mathrm{~A}$ mutants impaired the inverse agonism potency of PF-05190457 (Fig. 5e and Supplementary Fig. 7a), suggesting that both E124 3.33 and R283 $3^{6.55}$ (referred to as the E-R motif) should play an important role in the constitutive activity of the ghrelin receptor and the action of the inverse agonist. 

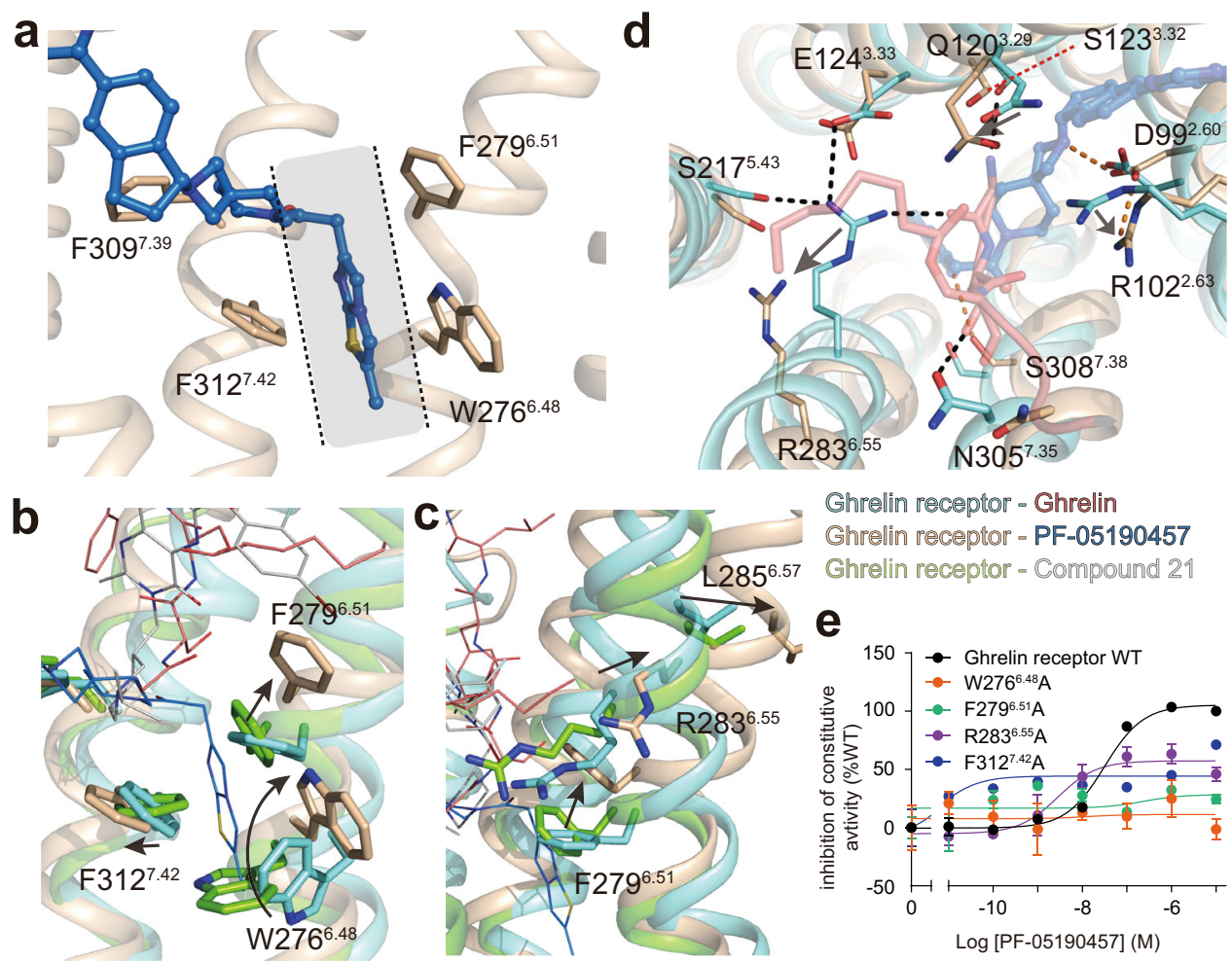

Ghrelin receptor - Ghrelin

Ghrelin receptor - PF-05190457

Ghrelin receptor - Compound 21

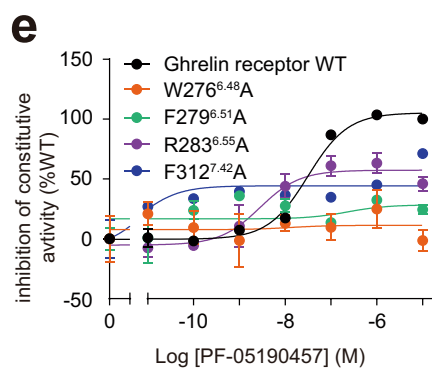

Fig. 5 Detailed mechanism of inverse agonism action on the ghrelin receptor. a The arm-2 group of PF-05190457 was observed to insert into the core of the receptor and was sandwiched by side chains from the hydrophobic cluster W2766.48-F2796.51-F3127.42 (WFF cluster). b Superposition of PF05190457-bound (wheat cartoon) and ghrelin-bound (aquamarine cartoon) structures shows that the WFF cluster exhibits obvious conformational displacements upon inverse agonist binding. c, d The inverse agonist PF-05190457 pushes outward movements of the extracellular end of TM6 (c), destroying the key polar interactions involved in activation (d). The polar networks are shown as black dotted lines (ghrelin-bound) and orange dotted lines (PF-05190457-bound). e Mutations of W2766.48, F2796.51, and F3127.42 in the ghrelin receptor significantly reduced the potency of inverse agonism. Data represent the mean \pm SEM from $n=3$ biologically independent experiments performed in triplicate. See also Supplementary Fig. 6 .

\section{Discussion}

The ghrelin receptor is reported to have high constitutive activity $^{25}$. To better understand the constitutive activity mechanism of the ghrelin receptor, we compared ghrelin receptors with different states as well as with previously described receptors with high basal activation, such as GPR52. The structure of GPR52 contains a built-in ECL2 region that is inserted into the orthosteric binding pocket ${ }^{50}$ (Supplementary Fig. 10a). In particular, Y185 ${ }^{\mathrm{ECL} 2}$ and H186 ${ }^{\mathrm{ECL} 2}$ act as built-in "agonist" for activating GPR52, thus resulting in a high level of basal activity of the receptor ${ }^{50}$ (Supplementary Fig. 10b). The structural superposition of GPR52 with the ghrelin receptor indicates that the ECL2 region of ghrelin receptor sits over the ligand-binding pocket (Supplementary Fig. 10c). Together with the structural comparison with ghrelin receptors with different types of ligands, our results suggest that polar networks such as the E-R motif and another notable hydrophobic WFF cluster should be required for the constitutive activity of receptors. More interestingly, our careful inspection of sequence alignment revealed that the equivalent E-R motif and aromatic cluster were also found in NTSR1, NTSR2, and GPR39 (Supplementary Fig. 11a). Previous reporting showed that NTSR2 and GPR39 display high constitutive activity ${ }^{31}$. Consistently, the ghrelin receptor has $\sim 50 \%$ maximal constitutive activity ${ }^{10}$, and the basal activity of NTSR2 was observed to be similar to that of the ghrelin receptor ${ }^{31}$, yet the constitutive activity was enhanced when mutating the $\mathrm{F}^{7.42} \mathrm{~A}$ in NTSR1. To further figure out the functional roles of the equivalent E-R motif and WFF cluster in NTSR1, we generated several mutations and carried out constitutive activity assays. The results of our measurement reveal that residues at positions 3.33 and 6.51 in NTSR1 should be engaged in constitutive activity of the receptor (Supplementary Fig. 11b) ${ }^{51}$. Therefore, we speculated that the receptors containing E-R motif and WFF cluster may contribute to their basal activity.

Numerous GPCRs have been reported to contain constitutive activity, and several structures of inverse agonist-bound GPCRs have been determined so far ${ }^{35-37,47}$. As shown in Supplementary Fig. 12b, inverse agonists in DRD2, 5-HT2aR, 5-HT2cR, and ghrelin receptor appear to extend deeply into the orthosteric pocket, forming directly hydrophobic interactions with the indole ring of the "switch" residue $W^{6.48}$. We note that the aromatic moiety of inverse agonists packs against either the left or right of $\mathrm{W}^{6.48}$ in the receptors mentioned above (Supplementary Fig. 12b). Methiothepin, RIT, and risperidone were observed to bind with the hydrophobic cavity on the left of $\mathrm{W}^{6.48}$ in 5HT2aR, 5-HT2cR, and DRD2, forming direct interactions with the $\mathrm{W}^{6.48}-\mathrm{F}^{6.51 / 6.52}-\mathrm{F}^{5.47}$ clusters. Whereas the PF-05190457 and IRL2500 bind to another hydrophobic cavity on the right of $\mathrm{W}^{6.48}$ in the ghrelin receptor and ETB receptor. Compared with the activated 5-HT2cR and DRD2 structures, the hydrophobic $\mathrm{W}^{6.48}$ $\mathrm{F}^{6.51 / 6.52}-\mathrm{F}^{5.47}$ cluster also notably displaced the structures of inverse agonist-bound receptors (Supplementary Fig. 12d-f). The deep binding conformation of the inverse agonist impeded the side-chain rotations of $\mathrm{W}^{6.48}$ and $\mathrm{F}^{6.44}$, restricting the conformational change of TM6 from inactive to active state.

In addition, sequence alignment and structural comparison of ghrelin receptors with 5-HT2aR, 5-HT2cR, DRD2 and ETB receptors revealed that the $\mathrm{E}^{3.33}-\mathrm{R}^{6.55}$ motif is not conserved (Supplementary Fig. 12a, c), and the distance between TM3 and TM6 appears to play a role in ligand selectivity. Collectively, in 
a

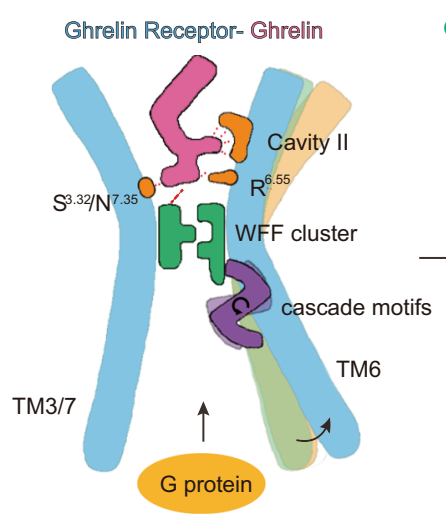

b

Ghrelin Receptor- Compound 21

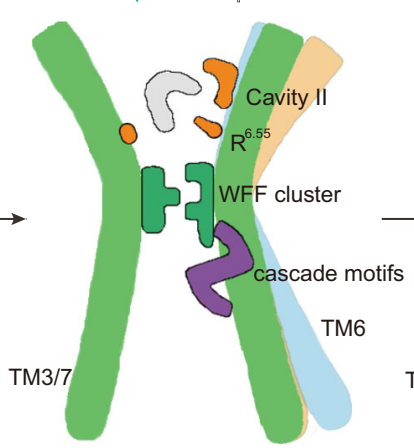
Ghrelin Receptor= PF05190457

Fig. 6 Summary model of ghrelin receptor bound with inverse agonist, agonist, and antagonist. Simple model for PF-05190457 (a), ghrelin (b), and compound 21 (c) bound to the ghrelin receptor. Some of the essential residues and modules are marked with different colors and patterns. The cascade motifs referred to the combination of the P-I-F motif, E-R-Y motif, and NPxxY motif.

the ghrelin receptor family (including ghrelin receptor, NTSR1, NTSR2, and GPR39), the conserved $\mathrm{E}^{3.33}-\mathrm{R}^{6.55}$ motif together with the WFF cluster is suggested to be essential for inverse agonist binding as well as agonist activation.

When our manuscript was under review, another study about the Gq-coupled ghrelin receptor was published, and it reported the structure of the ghrelin-bound receptor complex ${ }^{39}$. Obviously, $\mathrm{Gly}^{+1}$ and $\mathrm{Ser}^{+2}$ of ghrelin inserted into the same orthosteric site of the receptor, whether binding to either Go or Gq. The backbone of the ghrelin peptide resembled the identical conformation. However, a subtle difference was the position of the octanoyl groups at $\mathrm{Ser}^{+3}$ in the two ghrelin peptides (Supplementary Fig. 8b). The acyl chain of $\mathrm{Ser}^{+3}$ extends towards TM5 in the Gobound receptor, while the octanoic tail stretches horizontally toward the gap between TM4 and TM5 and five carbons of the octanoyl group can be placed in the density in the Gq-bound state, reflecting a presumptive dynamic character of acyl modification in the ghrelin receptor (Supplementary Fig. 8b). Coincidentally, previous literature has proven the dynamic characteristics of ghrelin receptors using NMR spectroscopy ${ }^{52}$. Compared with the available structure of the ghrelin peptide, the disordered C-terminus of the peptide folds into $a$-helix when ghrelin binds to its receptor (Supplementary Fig. 8c), displaying the dynamic conformation of the peptide. Therefore, it is not hard to speculate that the octanoyl group of ghrelin could behave in variable conformations. In agreement with this speculation, molecular simulation courses and NMR data indicated some degree of conformational and local dynamics of the ghrelin peptide in the ligand-binding pocket ${ }^{53}$.

In this study, we present the structures of ghrelin receptors in complex with the inverse agonist PF-05190457 as well as in complex with endogenous ghrelin and Go protein coupling. Combined with the inverse agonist-, agonist- and antagonistbound structures, the molecular mechanism of the activation of ghrelin receptor has gradually emerged, and it can be summarized as follow: The binding of ghrelin peptide to the receptor contracts the extracellular TM bundles and may change the orientation of the polar network and hydrophobic core including E-R motif and WFF cluster, further expanding the intracellular end of TM6 and allowing the ghrelin receptor to interact with $G$ proteins by rearranging the cascade motifs (including PIF motif, ERY motif, and NPxxY motif) (Fig. 6a). In addition, the binding of the antagonist occupies the orthosteric site and maintains the conformation of the E-R motif and WFF cluster (Fig. 6b). However, the binding of PF-05190457 will break the tight conformation of the WFF cluster, push against the extracellular TM6 bundle, and contract the intracellular end of the TM6 helix to close the Gprotein-binding pocket (Fig. $6 \mathrm{c}$ ).

Taken together, the discovery of constitutive receptor activity and inverse agonism extends the knowledge of GPCR pharmacology, which may help pharmacologists to achieve a greater degree of control over receptor function. Our study provides insights into the detailed mechanism of ghrelin receptor binding to inverse agonists and agonists, and it may pave the way for designing specific ligands targeting ghrelin receptors.

\section{Methods}

Construct design and expression. For crystallization construct ghrelin receptorbRIL, the wild-type human ghrelin receptor cDNA gene (UniProt accession: Q92847) was cloned into a modified pFastBacl (Invitrogen) baculovirus expression vector with the haemagglutinin (HA) signal sequence followed by a Flag epitope tag at the $\mathrm{N}$-terminus and a $10 \times \mathrm{His}$ tag at the $\mathrm{C}$-terminus. To facilitate receptor expression and crystallization, the $\mathrm{N}$-terminal 34 residues and $\mathrm{C}$-terminal residues after P342 were removed, TEV protease recognition sites were introduced before the residue Leu35 at N-terminus and before the residue F343 at C-terminus. Residues R244 $4^{5.70}-\mathrm{S} 252^{6.24}$ of the intracellular loop 3 (ICL3) were replaced with the thermostabilized apocytochrome $b_{562}$ RIL (bRIL) (PDB: 1M6T). Furthermore, mutations $\mathrm{T} 130^{3.39} \mathrm{~K}$ and $\mathrm{N} 188^{\mathrm{ECL} 2} \mathrm{Q}$ were introduced to improve thermostability and homogeneity. The final construct of the ghrelin receptor was transfected into DH10Bac ${ }^{\text {Tx }}$ Escherichia coli to produce a recombinant baculovirus with the Bac-toBac system (Invitrogen). The recombinant baculovirus was used to infect Sf9 insect cell culture at a cell density of $2.5 \times 10^{6}$ cells per $\mathrm{ml}^{-1}$. Infected cells were grown for $48 \mathrm{~h}$ at $27^{\circ} \mathrm{C}$ before harvesting, and the cell pellets were stored at $-80^{\circ} \mathrm{C}$ for future use.

For cryo-EM constructs, the full-length of wild-type human ghrelin receptor was subcloned into pFastBacl vector with an $\mathrm{N}$-terminal FLAG tag and C-terminal $10 \times$ His tag. We used the NanoBiT tethering strategy, in which the C-terminus of the ghrelin receptor was directly attached to the LgBiT subunit followed by a TEV protease cleavage site and a double MBP tag. G $\beta 1$ was fused with a C-terminal $\mathrm{HiBiT}$, together with $\mathrm{G} \gamma 2$ were cloned into pFastBac dual vector. An engineered human Gaol with Gaol H domain deletion, named miniGaol was cloned into pFastBacl according to published literature ${ }^{33}$. The ghrelin-induced ghrelin receptor activity was measured by NanoBiT-G-protein dissociation assay using a chimeric Gaio protein according to the previous publication except for replacement Gaqo with Gaio ${ }^{54}$. The Gaio were generated by replacing the six amino acids of the C-terminal of Gai with those from GaoAl. Other constructs including the full-length and various site-directed mutagenesis human ghrelin receptors were cloned into pcDNA3.1 vector for NanoBiT-G-protein dissociation assay. Ghrelin receptor, miniGaol, and G $\beta 1 \gamma 2$ were co-expressed in Sf9 insect cells (Expression System) using the Bac-to-Bac baculovirus expression system (ThermoFisher). The cell pellets were collected by centrifugation $48 \mathrm{~h}$ post infection and stored at $-80^{\circ} \mathrm{C}$ until use.

Purification of ghrelin receptor-bRIL protein. The cell pellets were lysed using a

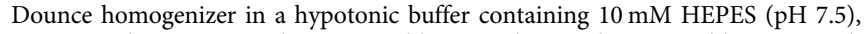
$20 \mathrm{mM} \mathrm{KCl}, 10 \mathrm{mM} \mathrm{MgCl} 2,160 \mu \mathrm{g} / \mathrm{ml}$ benzamidine, and $100 \mu \mathrm{g} / \mathrm{ml}$ leupeptin. The cell membranes were isolated by ultracentrifugation at $100,000 \times g$ for $30 \mathrm{~min}$ at $4{ }^{\circ} \mathrm{C}$. Washing of the membranes was performed by two rounds of Dounce homogenization and centrifugation in a high-osmolarity buffer containing $10 \mathrm{mM}$ 
HEPES (pH 7.5), $1.0 \mathrm{M} \mathrm{NaCl}, 20 \mathrm{mM} \mathrm{KCl}$, and $10 \mathrm{mM} \mathrm{MgCl}_{2}, 160 \mu \mathrm{g} / \mathrm{ml}$ benzamidine, and $100 \mu \mathrm{g} / \mathrm{ml}$ leupeptin. Purified membranes were incubated with $10 \mu \mathrm{M}$ PF-05190457 (Tocris) and $2 \mathrm{mg} / \mathrm{ml}$ iodoacetamide in hypotonic buffer for $2 \mathrm{~h}$. The membranes were then solubilized in a solubilization buffer containing $10 \mu \mathrm{M}$ PF05190457, $50 \mathrm{mM}$ HEPES (pH 7.5), $500 \mathrm{mM} \mathrm{NaCl}, 10 \%(\mathrm{v} / \mathrm{v})$ glycerol, $1 \%(\mathrm{w} / \mathrm{v}) \mathrm{n}-$ dodecyl-13-D-maltopyranoside (DDM), $0.2 \%$ cholesteryl hemisuccinate (CHS), and $0.2 \%(\mathrm{w} / \mathrm{v})$ sodium cholate, $160 \mu \mathrm{g} / \mathrm{ml}$ benzamidine, $100 \mu \mathrm{g} / \mathrm{ml}$ leupeptin for $2.5 \mathrm{~h}$ at $4{ }^{\circ} \mathrm{C}$, followed by ultracentrifugation at $125,000 \times g$ for $30 \mathrm{~min}$ at $4^{\circ} \mathrm{C}$. The supernatant was incubated with TALON IMAC resin (TaKaRa) in a batch overnight at $4^{\circ} \mathrm{C}$. After binding, the resin was collected by centrifugation at $500 \times g$ for $5 \mathrm{~min}$, resuspended with wash buffer (50 mM HEPES pH 7.5, $500 \mathrm{mM} \mathrm{NaCl}, 0.1 \%$ lauryl maltose neopentyl glycol (LMNG; Anatrace), $0.02 \%$ sodium cholate, $0.02 \%$ CHS, $5 \%(\mathrm{v} / \mathrm{v})$ glycerol) supplemented with $160 \mu \mathrm{g} / \mathrm{ml}$ benzamidine, $100 \mu \mathrm{g} / \mathrm{ml}$ leupeptin, $10 \mathrm{mM}$ imidazole, $1 \mu \mathrm{M}$ PF-05190457 and was repeated one more time. Then the resin was loaded on a glass column and slowly washed with wash buffer containing $160 \mu \mathrm{g} / \mathrm{ml}$ benzamidine, $100 \mu \mathrm{g} / \mathrm{ml}$ leupeptin, $15 \mathrm{mM}$ imidazole, and $1 \mu \mathrm{M}$ PF-05190457 for gradually exchanging to LMNG. The protein was eluted with $10 \mathrm{ml}$ wash buffer containing $200 \mathrm{mM}$ imidazole, $10 \mu \mathrm{M}$ PF-05190457. The $\mathrm{N}$-terminal FLAG tag and C-terminal $10 \times$ His tag were cleaved by TEV protease for $6 \mathrm{~h}$ at $4{ }^{\circ} \mathrm{C}$. Finally, the receptor was run on a Superdex 200 size-exclusion column (GE Healthcare) with buffer containing $20 \mathrm{mM}$ HEPES (pH 7.5), $150 \mathrm{mM}$ $\mathrm{NaCl}, 0.02 \%$ LMNG, $0.004 \% \mathrm{CHS}$, and $10 \mu \mathrm{M}$ PF-05190457.

\section{Crystallization, data collection, and structure determination. The purified} receptor-PF-05190457 complex was concentrated to $>60 \mathrm{mg} / \mathrm{ml}$ using a $100-\mathrm{kDa}$ cutoff Vivaspin concentrator (Sartorius). The initial crystallization screen was set up using the lipidic cubic phase (LCP) method ${ }^{55}$. The sample of the complex was mixed with the lipid (monoolein and cholesterol at 10:1 by mass) at a weight ratio of 2:3 using a syringe mixing apparatus at room temperature ${ }^{56}$. The mesophase was then dispensed into glass sandwich plates in $40 \mathrm{nl}$ drops and overlaid with $800 \mathrm{nl}$ precipitant solution using a Gryphon LCP robot (Art Robbins Instruments). The full-size crystals of ghrelin receptor were grown over 1 week at $20^{\circ} \mathrm{C}$ in the following overlay precipitant condition: 25-6\% PEG300, 100 mM HEPES pH 7.0, $100-150 \mathrm{mM} \mathrm{NH}_{4} \mathrm{~F}$. Finally, the LCP crystals were frozen quickly in liquid nitrogen after harvesting.

The X-ray diffraction data were collected at beamline 32XU at SPring-8, Hyogo, Japan, using a beam size of $10 \mu \mathrm{m}$ and a Pilatus $3 \mathrm{M}$ detector (X-ray wavelength $1.0000 \AA$ ). The data-collection strategy was designed and performed on the basis of initial raster results as described previously ${ }^{57}$. Full datasets of PF-05190457-bound ghrelin receptor were assembled from 23 crystals owing to the radiation damage of crystals. Diffraction images were indexed, integrated, and scaled using $\mathrm{XDS}^{58}$ and merged using SCALA. The resolution limit was set to $2.94 \AA$. Data-collection statistics are shown in Supplementary Table 1. The structure of the PF-05190457bound ghrelin receptor was determined by molecular replacement with PHASER ${ }^{59}$, using ghrelin receptor (receptor only, PDB: 6KO5) and bRIL (PDB: 1M6T) as independent search models. The refinement and manual building were performed by PHENIX ${ }^{59}$ and $\mathrm{COOT}^{60}$, respectively. The refinement parameter for ligand PF05190457 was generated with the PRODRG ${ }^{61}$ web server. Refinement statistics are reported in Supplementary Table 1. Figures were generated using PyMOL (https:// pymol.org).

Ghrelin-bound ghrelin receptor-Go complex formation and purification. The cell pellets were lysed in a buffer containing $20 \mathrm{mM}$ HEPES, pH 7.5, $100 \mathrm{mM} \mathrm{NaCl}$, and $2 \mathrm{mM} \mathrm{MgCl}$ supplemented with EDTA-free protease inhibitor cocktail

(Bimake) by dounce homogenization. The complex formation was initiated by

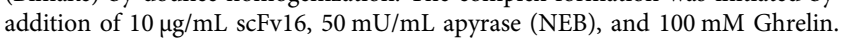
After incubation at room temperature for $1.5 \mathrm{~h}$, the membranes were solubilized by addition of $0.5 \%(\mathrm{w} / \mathrm{v})$ lauryl maltose neopentyl glycol (LMNG, Anatrace) and $0.1 \%(\mathrm{w} / \mathrm{v})$ cholesteryl hemisuccinate TRIS salt (CHS, Anatrace) for $2 \mathrm{~h}$ at $4{ }^{\circ} \mathrm{C}$. The supernatant was isolated by centrifugation at $30,000 \times g$ for $30 \mathrm{~min}$ and then incubated $1 \mathrm{~h}$ at $4{ }^{\circ} \mathrm{C}$ with pre-equilibrated MBP resin. After binding, the resin was washed with 15 column volumes of $20 \mathrm{mM}$ HEPES pH 7.5, $100 \mathrm{mM} \mathrm{NaCl}, 2 \mathrm{mM}$ $\mathrm{MgCl}_{2}, 0.01 \%$ (w/v) LMNG, $0.002 \%$ (w/v) CHS, and $10 \mathrm{mM}$ Ghrelin. The complex was eluted with 5 column volumes of $20 \mathrm{mM}$ HEPES pH 7.5, $100 \mathrm{mM} \mathrm{NaCl}, 2 \mathrm{mM}$ $\mathrm{MgCl}_{2}, 0.01 \%$ (w/v) LMNG, $0.002 \%$ (w/v) CHS, $10 \mathrm{mM}$ maltose, and $10 \mathrm{mM}$ ghrelin.

The protein was then concentrated and loaded onto a Superose $\mathrm{e}^{\mathrm{mx}} 6$ Increase column (GE Healthcare) pre-equilibrated with buffer containing $20 \mathrm{mM}$ HEPES pH 7.5, $100 \mathrm{mM} \mathrm{NaCl}, 0.00075 \%$ (w/v) LMNG, $0.00025 \%$ (w/v) glyco-diosgenin (GDN, Anatrace), $0.0002 \%(\mathrm{w} / \mathrm{v}$ ) CHS and $10 \mathrm{mM}$ ghrelin. The fractions for the monomeric complex were collected and concentrated for electron microscopy experiments.

Cryo-EM grid preparation and data collection. For the cryo-EM grids preparation, $3 \mathrm{uL}$ purified protein ghrelin receptor-miniGaol-G $\beta 1 \gamma 2$ complex at the concentration of about $15 \mathrm{mg} / \mathrm{mL}$ were applied individually to a glow discharged holey carbon EM grid (Quantifoil, Au300 R1.2/1.3) in a Vitrobot chamber (FEI Vitrobot Mark IV). The grids were blotted for $3.0 \mathrm{~s}$ with a blot force of 3 at $4{ }^{\circ} \mathrm{C}$,
$100 \%$ humidity, and then plunge-frozen in liquid ethane using Vitrobot Mark IV (Thermo Fischer Scientific). Cryo-EM data collection was performed on a Titan Krios at $300 \mathrm{kV}$ accelerating voltage in the Center of Cryo-Electron Microscopy, Zhejiang University (Hangzhou, China). Micrographs were recorded using a Gatan K2 Summit detector in counting mode with a pixel size of $1.014 \AA$ using the SerialEM software. The total exposure time was $8 \mathrm{~s}$ and 40 frames were recorded per micrograph.

Cryo-EM data processing. Image stacks for ghrelin receptor-miniGaol-G $\beta 1 \gamma^{2}$ complex were subjected to beam-induced motion correction using MotionCor2.162. Contrast transfer function (CTF) parameters were estimated by Gctfv1.1863. The following data processing was performed using RELION-3.0beta $2^{64}$. Auto-picking automated particle selection using Gaussian blob detection produced 2,824,307 particles. The particles were subjected to four rounds of 3D classifications on the complex and selected the best-resolved class. Further 3D classification focusing the alignment on the ghrelin receptor produced a highquality subset accounting for 230,306 particles, which were subsequently subjected to 3D refinement, CTF refinement, and Bayesian polishing. The final refinement generated a map with an indicated global resolution of $2.8 \AA$ at a Fourier shell correlation of 0.143. Local resolution was determined using the Bsoft package with half maps as input maps ${ }^{65}$.

Cryo-EM model building, refinement, and validation. The crystal structure of the ghrelin receptor ${ }^{30}$ (PDB: 6KO5) was used as an initial model for model rebuilding and refinement against the electron microscopy map of ghrelin receptor-miniGaolG $\beta 1 \gamma 2$ complex. The BCM-GPR97-Go complex ${ }^{33}$ (PDB 7D76) was to generate the initial models of Go, G $\beta \gamma$, and scFV16. Ligand and lipids coordinate and geometry restraints were generated using phenix. elbow. Models were docked into the EM density map using UCSF Chimera (https://www.cgl.ucsf.edu/chimera/). This starting model was then subjected to iterative rounds of manual adjustment and automated refinement in $\operatorname{Coot}^{66}$ and Phenix $10^{59}$, respectively.

The final refinement statistics were validated using the module "comprehensive validation (cryo-EM)" in PHENIX. To monitor the potential over-fitting in model building, FSCwork and FSCtest were determined by refining the 'shaken' models against unfiltered half-map-1 and calculating the FSC of the refined models against unfiltered half-map-1 and half-map-2. Structural figures were prepared in Chimera (https:// www.cgl.ucsf.edu/chimera), ChimeraX11 17,68 and PyMOL (https://pymol.org/). The final refinement statistics are provided in Supplementary Table 2.

IP1 accumulation assays. To measure the activity of inverse agonist PF-05190457 (Tocris, Cat. No. 6350), we carried out IP1 accumulation assays for ghrelin receptor independent of agonist. The agonist ghrelin and antagonist compound 21 were also performed as the control. The cDNA of ghrelin receptor subcloned into pcDNA3.1(+) expression vector with a HA signal sequence followed by a Flag tag at the N-terminus. Point mutations used in our study were generated by using Q5 site-Directed Mutagenesis kit (NEB). All the constructs were verified by sequencing. The constructs were expressed in HEK293 cells using PEI transfection reagent (YEASEN, 40815es03) according to the manufacturer's instruction. Cells were harvested $48 \mathrm{~h}$ post transfection.

IP accumulation was measured using Cisbio IP1 assay kit (Cisbio, 62IPAPEB), which has been previously described ${ }^{32}$. In brief, the harvested cells were distributed in a low volume 96-well dish and stimulated with increased concentration of inverse agonist PF-05190457, agonist ghrelin peptide or antagonist compound 21 containing $10 \mathrm{nM}$ ghrelin peptide at $37^{\circ} \mathrm{C}$ for $2 \mathrm{~h}$. After that, d2-labeled IP1 and cryptate-labeled anti-IP1 monoclonal antibody dissolved in Lysis Buffer were added to the wells. After $1 \mathrm{~h}$ incubation at room temperature. IP1 was quantified using Synergy H1 microplate reader (BioTek) with excitation at $320 \mathrm{~nm}$, emission at $620 \mathrm{~nm}$, and $665 \mathrm{~nm}$. The accumulation of IP1 was calculated according to a standard dose-response curve in GraphPad Prism 8 (GraphPad Software). Data were represented as the mean \pm SEM from three independent experiments and all experiments were repeated at least three times.

NanoBiT-G-protein dissociation assay. G-protein activation was detected by a NanoBiT-G-protein dissociation assay ${ }^{69}$. In brief, HEK293T cells were plated in each well of a six-well plate at a concentration of 0.3 million $/ \mathrm{ml}(2 \mathrm{~mL}$ per well). Plasmid transfection was performed with a mixture of $400 \mathrm{ng}$ Gaio-LgBiT, $500 \mathrm{ng}$ G $\gamma$-SmBiT, 500 ng G $\beta, 600$ ng ghrelin receptor by Lipofectamine 2000 (ThermoFisher Scientific) in $200 \mu \mathrm{L}$ of Opti-MEM (Gibco). After 1 day of transfection, cells in the six-well plate were digested and resuspended in complete medium DMEM (5\% FBS, $1 \%$ antibiotic) and plated in a 96-well flat-bottomed white microplate. After $24 \mathrm{~h}$, the cells were washed twice with D-PBS and incubated in $40 \mu \mathrm{L}$ of $5 \mu \mathrm{M}$ coelenterazine 400a (Maokangbio) solution diluted $0.01 \%$ BSA and $5 \mathrm{mM}$ HEPES (pH 7.5)-containing HBSS (assay buffer) for $1 \mathrm{~h}$ at room temperature. Baseline luminescence was measured using a luminescent microplate reader (Tecan). Ghrelin (5x, diluted in the assay buffer) was added to the cells $(10 \mu \mathrm{L})$ and incubated for 3-5 $\mathrm{min}$ at room temperature before the second measurement. The ligand-induced signal ratio was normalized to the baseline luminescence and fold- 
change signals over vehicle treatment were used to show G-protein dissociation response.

Enzyme-linked immunosorbent assay (ELISA). Cell surface expression of the receptor subunits was detected by ELISA. Plasmids corresponding to WT and mutant ghrelin receptors were transfected as described above. After transfection, cells were reseeded onto cell adherent reagent (Applygen) treated 96-well plates at a density of $3 \times 10^{4}$ cells per well. Twenty-four hours later, cells were washed with PBS and fixed with $10 \%$ formaldehyde for $10 \mathrm{~min}$ followed by three times washing with PBS. Following fixation, cells were blocked with blocking buffer (1\% BSA in PBS) for $1 \mathrm{~h}$ at RT. Afterward, plates were incubated with a 1:10,000 dilution of anti-FLAG M2 HRPconjugated monoclonal antibody (SigmaAldrich) in blocking buffer for another $1 \mathrm{~h}$ at RT. After careful washing, $80 \mu \mathrm{L} /$ well diluent SuperSignal Elisa Femto Maximum Sensitivity Substrate (ThermoFisher Scientific) was added, and the luminescence was measured using a luminescence microplate reader (Tecan).

Synthesis. All solvents and chemicals used for compound $\mathbf{2 1}$ synthesis were reagent grade and supplied by commercial sources. Silica gel thin-layer chromatography was performed on pre-coated plates GF-254 (Qingdao HaiYang, China). The compound purity and characterization were established by a combination of liquid chromatography-mass spectroscopy (LCMS) and nuclear magnetic resonance (NMR) analytical techniques. The LCMS using Waters Acquity_Arc-2489Qda (Column: Xbridge C18; Column size: $3.5 \mu \mathrm{m} 2.1 \times 50 \mathrm{~mm}$, mobile phase: A: $(0.1 \% \mathrm{FA}) \mathrm{H}_{2} \mathrm{O}, \mathrm{B}$ : MeCN; gradient $\mathrm{B} \%$ : as Acq. operating in $\mathrm{ES}(+)$ ionization mode; $T=40{ }^{\circ} \mathrm{C}$; flow rate $=1.0 \mathrm{~mL} / \mathrm{min}$; detected wavelength, $220 \mathrm{~nm}$ ). The ${ }^{1} \mathrm{H}-\mathrm{NMR}$ spectra were recorded on Burker AVANCEIII $600 \mathrm{MHz}$ (Bruker Company). Chemical shifts are provided in ppm $(\delta)$. Compound $\mathbf{2 1}$ was prepared as follow (see also in Supplementary Fig. 13a):

Briefly, a mixture of 3-amino-6-chloropyridine-2-carboxylicacid $(0.5 \mathrm{~g}, 2.9 \mathrm{mmol})$, tert-butyl (R)-3-(aminomethyl)piperidine-1-carboxylate $(0.8 \mathrm{~g}, 3.7 \mathrm{mmol}), \mathrm{BOP}$ (Tri(dimethylamino)benzotriazol-1-yloxyphosphonium hexafluorophosphate) (1.5 g, $3.4 \mathrm{mmol})$ and TEA $(0.9 \mathrm{~g}, 8.7 \mathrm{mmol})$ in DCM $(12.5 \mathrm{~mL})$ was stirred overnight at room temperature. The reaction mixture was washed with saturated sodium bicarbonate solution, saturated sodium chloride solution, and concentrated. The residue was purified by thin-layer chromatography (TLC) $(\mathrm{DCM} / \mathrm{MeOH}=15 / 1)$ to give the title compound $3(1 \mathrm{~g}, 93.5 \%)$ as a yellow solid.

Compound 3 ( $1 \mathrm{~g}, 2.7 \mathrm{mmol})$ was dissolved in Ethyl orthoacetate $(2.2 \mathrm{~g}$, $13.6 \mathrm{mmol})$. Added HOAc (163 mg, $2.7 \mathrm{mmol})$ in the solution and stirred at $135^{\circ} \mathrm{C}$ for $3 \mathrm{~h}$. The reaction mixture was concentrated in a vacuum to give the title compound $4(0.86 \mathrm{~g}, 81.1 \%)$ as a white solid. Compound $4(0.86 \mathrm{~g}, 2.2 \mathrm{mmol})$, 4bromo-2-fluorophenol $(1.25 \mathrm{~g}, 6.6 \mathrm{mmol})$ and Caesium carbonate $(2.2 \mathrm{~g}, 6.6 \mathrm{mmol})$ were dissolved in DMF $(10 \mathrm{~mL})$ and stirred $6 \mathrm{~h}$ at $90^{\circ} \mathrm{C}$. The reaction mixture was extracted by the saturated sodium bicarbonate and EAC. The residue was dried over $\mathrm{Na}_{2} \mathrm{SO}_{4}$ and concentrated in a vacuum to afford the title compound 6 ( $1 \mathrm{~g}$ $83.3 \%)$ as yellow solid.

Added $\mathrm{EA} / \mathrm{HCl}(3 \mathrm{~mL})$ to the solution of compound $6(0.5 \mathrm{~g} 0.9 \mathrm{mmol})$ dissolved in EA $(3 \mathrm{~mL})$ stirred $0.5 \mathrm{~h}$ at room temperature. The reaction mixture was concentrated in a vacuum. The residue was dissolved in $\mathrm{CH}_{3} \mathrm{CN}(10 \mathrm{~mL})$, then added 2-iodopropane $(0.5 \mathrm{~g}, 2.7 \mathrm{mmol})$ and $\mathrm{K}_{2} \mathrm{CO}_{3}(0.5 \mathrm{~g}, 4.6 \mathrm{mmol})$ stirred $6 \mathrm{~h}$ at $70{ }^{\circ} \mathrm{C}$. The reaction mixture was extracted with EAC, dried over $\mathrm{Na}_{2} \mathrm{SO}_{4}$ and concentrated. The residue was purified by TLC $(\mathrm{DCM} / \mathrm{MeOH}=20 / 1)$ to afford the compound $21(0.3 \mathrm{~g} 67.1 \%)$ as a white solid. The compound 21 was measured to have $98.8 \%$ purity before the experiment. ${ }^{1} \mathrm{H}-\mathrm{NMR}(600 \mathrm{MHz}, \mathrm{CDCl} 3): \delta 7.98(\mathrm{~d}$, $\mathrm{J}=13.2 \mathrm{~Hz}, 1 \mathrm{H}), 7.26-7.39(\mathrm{~m}, 4 \mathrm{H}), 4.03(\mathrm{~s}, 2 \mathrm{H}), 2.69-2.73(\mathrm{~m}, 6 \mathrm{H}), 2.13-2.24$ $(\mathrm{m}, 3 \mathrm{H}), 1.69-1.74(\mathrm{~m}, 3 \mathrm{H}), 1.23-1.27(\mathrm{~m}, 1 \mathrm{H}), 1.01-1.04(\mathrm{dd}, \mathrm{J}=4.8,9 \mathrm{~Hz}, 6 \mathrm{H})$. MS $m / z\left(\mathrm{ES}^{+}\right)=489.13$ (Supplementary Fig. 13b-d).

Statistics and reproducibility. All functional study data were analyzed using Prism 8 (GraphPad) and presented as means \pm SEM. from at least $n=3$ biologically independent experiments performed in triplicate. Concentration-response curves were evaluated with a standard dose-response curve. Statistical differences were determined by two-sided, one-way ANOVA with Dunnett's multiple comparisons test.

Reporting summary. Further information on research design is available in the Nature Research Reporting Summary linked to this article.

\section{Data availability}

The structural data generated in this study have been deposited in the Protein Data Bank (http://www.pdb.org/) under accession number 7F83 for the PF-05190457-ghrelin receptor, 7W2Z and Electron Microscopy Data Bank (EMDB) accession number EMD32268 for the ghrelin-ghrelin receptor-Go complex. All the other data generated in this study are provided in the Supplementary information and source data files. Source data are provided with this paper.

Received: 27 July 2021; Accepted: 29 December 2021; Published online: 13 January 2022

\section{References}

1. Berg, K. A., Harvey, J. A., Spampinato, U. \& Clarke, W. P. Physiological relevance of constitutive activity of 5-HT2A and 5-HT2C receptors. Trends Pharmacol. Sci. 26, 625-630 (2005).

2. Meye, F. J., van Zessen, R., Smidt, M. P., Adan, R. A. \& Ramakers, G. M. Morphine withdrawal enhances constitutive $\mu$-opioid receptor activity in the ventral tegmental area. J. Neurosci. 32, 16120-16128 (2012).

3. Tam, J. et al. Peripheral cannabinoid-1 receptor inverse agonism reduces obesity by reversing leptin resistance. Cell. Metab. 16, 167-179 (2012).

4. Arrang, J. M., Morisset, S. \& Gbahou, F. Constitutive activity of the histamine H3 receptor. Trends Pharmacol. Sci. 28, 350-357 (2007).

5. Smit, M. J. et al. Pharmacogenomic and structural analysis of constitutive $\mathrm{g}$ protein-coupled receptor activity. Annu. Rev. Pharmacol. Toxicol. 47, 53-87 (2007).

6. Soudijn, W., van Wijngaarden, I. \& Ijzerman, A. P. Structure-activity relationships of inverse agonists for G-protein-coupled receptors. Med. Res. Rev. 25, 398-426 (2005).

7. de Ligt, R. A., Kourounakis, A. P. \& AP, I. J. Inverse agonism at G proteincoupled receptors: (patho)physiological relevance and implications for drug discovery. Br. J. Pharmacol. 130, 1-12 (2000).

8. Bond, R. A. \& Ijzerman, A. P. Recent developments in constitutive receptor activity and inverse agonism, and their potential for GPCR drug discovery. Trends Pharmacol. Sci. 27, 92-96 (2006).

9. Howard, A. D. et al. A receptor in pituitary and hypothalamus that functions in growth hormone release. Science 273, 974-977 (1996)

10. Damian, M. et al. High constitutive activity is an intrinsic feature of ghrelin receptor protein: a study with a functional monomeric GHS-R1a receptor reconstituted in lipid discs. J. Biol. Chem. 287, 3630-3641 (2012).

11. Theander-Carrillo, C. et al. Ghrelin action in the brain controls adipocyte metabolism. J. Clin. Investig. 116, 1983-1993 (2006).

12. Yanagi, S., Sato, T., Kangawa, K. \& Nakazato, M. The homeostatic force of ghrelin. Cell. Metab. 27, 786-804 (2018).

13. Davis, J. Hunger, ghrelin and the gut. Brain Res. 1693, 154-158 (2018).

14. Kojima, M. \& Kangawa, K. Ghrelin: more than endogenous growth hormone secretagogue. Ann. N Y Acad. Sci. 1200, 140-148 (2010).

15. Evron, T. et al. G Protein and $\beta$-arrestin signaling bias at the ghrelin receptor. J. Biol. Chem. 289, 33442-33455 (2014).

16. Kojima, M. et al. Ghrelin is a growth-hormone-releasing acylated peptide from stomach. Nature 402, 656-660 (1999).

17. Yang, J., Brown, M. S., Liang, G., Grishin, N. V. \& Goldstein, J. L. Identification of the acyltransferase that octanoylates ghrelin, an appetitestimulating peptide hormone. Cell 132, 387-396 (2008).

18. Heppner, K. M. et al. Acylation type determines ghrelin's effects on energy homeostasis in rodents. Endocrinology 153, 4687-4695 (2012).

19. Yang, J., Zhao, T. J., Goldstein, J. L. \& Brown, M. S. Inhibition of ghrelin O-acyltransferase (GOAT) by octanoylated pentapeptides. Proc. Natl Acad. Sci. USA 105, 10750-10755 (2008).

20. Lu, S. C. et al. An acyl-ghrelin-specific neutralizing antibody inhibits the acute ghrelin-mediated orexigenic effects in mice. Mol. Pharmacol. 75, 901-907 (2009).

21. Wortley, K. E. et al. Absence of ghrelin protects against early-onset obesity. J. Clin. Investig. 115, 3573-3578 (2005)

22. Sun, Y., Butte, N. F., Garcia, J. M. \& Smith, R. G. Characterization of adult ghrelin and ghrelin receptor knockout mice under positive and negative energy balance. Endocrinology 149, 843-850 (2008).

23. Colldén, G., Tschöp, M. H. \& Müller, T. D. Therapeutic potential of targeting the ghrelin pathway. Int. J. Mol. Sci. 18, 798 (2017)

24. Els, S., Beck-Sickinger, A. G. \& Chollet, C. Ghrelin receptor: high constitutive activity and methods for developing inverse agonists. Methods Enzymol. 485, 103-121 (2010)

25. Holst, B., Cygankiewicz, A., Jensen, T. H., Ankersen, M. \& Schwartz, T. W. High constitutive signaling of the ghrelin receptor-identification of a potent inverse agonist. Mol. Endocrinol. 17, 2201-2210 (2003).

26. M'Kadmi, C. et al. N-terminal liver-expressed antimicrobial peptide 2 (LEAP2) region exhibits inverse agonist activity toward the ghrelin receptor. $J$. Med. Chem. 62, 965-973 (2019)

27. Bhattacharya, S. K. et al. Discovery of PF-5190457, a potent, selective, and orally bioavailable ghrelin receptor inverse agonist clinical candidate. ACS Med. Chem. Lett. 5, 474-479 (2014).

28. Denney, W. S., Sonnenberg, G. E., Carvajal-Gonzalez, S., Tuthill, T. \& Jackson V. M. Pharmacokinetics and pharmacodynamics of PF-05190457: the first oral ghrelin receptor inverse agonist to be profiled in healthy subjects. $\mathrm{Br}$. J. Clin. Pharmacol. 83, 326-338 (2017).

29. Kong, J. et al. Pharmacological characterization of the first in class clinical candidate PF-05190457: a selective ghrelin receptor competitive antagonist with inverse agonism that increases vagal afferent firing and glucosedependent insulin secretion ex vivo. Br. J. Pharmacol. 173, 1452-1464 (2016).

30. Shiimura, Y. et al. Structure of an antagonist-bound ghrelin receptor reveals possible ghrelin recognition mode. Nat. Commun. 11, 4160 (2020). 
31. Holst, B. et al. Common structural basis for constitutive activity of the ghrelin receptor family. J. Biol. Chem. 279, 53806-53817 (2004).

32. Yan, W. et al. Structure of the human gonadotropin-releasing hormone receptor GnRH1R reveals an unusual ligand binding mode. Nat. Commun. 11, 5287 (2020).

33. Ping, Y. Q. et al. Structures of the glucocorticoid-bound adhesion receptor GPR97-G(o) complex. Nature 589, 620-626 (2021).

34. Duan, J. et al. Cryo-EM structure of an activated VIP1 receptor-G protein complex revealed by a NanoBiT tethering strategy. Nat. Commun. 11, 4121 (2020).

35. Wang, S. et al. Structure of the D2 dopamine receptor bound to the atypical antipsychotic drug risperidone. Nature 555, 269-273 (2018).

36. Nagiri, C. et al. Crystal structure of human endothelin ET(B) receptor in complex with peptide inverse agonist IRL2500. Commun. Biol. 2, 236 (2019).

37. Shao, Z. et al. High-resolution crystal structure of the human CB1 cannabinoid receptor. Nature 540, 602-606 (2016).

38. Kung, D. W. et al. Identification of spirocyclic piperidine-azetidine inverse agonists of the ghrelin receptor. Bioorg. Med. Chem. Lett. 22, 4281-4287 (2012).

39. Wang, Y. et al. Molecular recognition of an acyl-peptide hormone and activation of ghrelin receptor. Nat. Commun. 12, 5064 (2021).

40. Ring, A. M. et al. Adrenaline-activated structure of $\beta 2$-adrenoceptor stabilized by an engineered nanobody. Nature 502, 575-579 (2013).

41. Xiao, P. et al. Ligand recognition and allosteric regulation of DRD1-Gs signaling complexes. Cell 184, 943-956.e918 (2021)

42. Ohgusu, H. et al. Ghrelin O-acyltransferase (GOAT) has a preference for nhexanoyl-CoA over n-octanoyl-CoA as an acyl donor. Biochem. Biophys. Res. Commun. 386, 153-158 (2009).

43. Gutierrez, J. A. et al. Ghrelin octanoylation mediated by an orphan lipid transferase. Proc. Natl Acad. Sci. USA 105, 6320-6325 (2008).

44. Krumm, B. E., White, J. F., Shah, P. \& Grisshammer, R. Structural prerequisites for G-protein activation by the neurotensin receptor. Nat. Commun. 6, 7895 (2015)

45. Zhang, H. et al. Structural basis for chemokine recognition and receptor activation of chemokine receptor CCR5. Nat. Commun. 12, 4151 (2021).

46. Kim, K. et al. Structure of a hallucinogen-activated Gq-coupled 5-HT(2A) serotonin receptor. Cell 182, 1574-1588.e1519 (2020).

47. Peng, Y. et al. 5-HT(2C) receptor structures reveal the structural basis of GPCR polypharmacology. Cell 172, 719-730.e714 (2018).

48. Hanson, M. A. et al. Crystal structure of a lipid G protein-coupled receptor. Science 335, 851-855 (2012).

49. Hua, T. et al. Crystal structures of agonist-bound human cannabinoid receptor CB(1). Nature 547, 468-471 (2017).

50. Lin, X. et al. Structural basis of ligand recognition and self-activation of orphan GPR52. Nature 579, 152-157 (2020).

51. Deluigi, M. et al. Complexes of the neurotensin receptor 1 with smallmolecule ligands reveal structural determinants of full, partial, and inverse agonism. Sci. Adv. 7, eabe5504 (2021).

52. Vortmeier, G. et al. Integrating solid-state NMR and computational modeling to investigate the structure and dynamics of membrane-associated ghrelin. PLOS ONE 10, e0122444 (2015).

53. Ferré, G. et al. Structure and dynamics of G protein-coupled receptor-bound ghrelin reveal the critical role of the octanoyl chain. Proc. Natl Acad. Sci. USA 116, 17525-17530 (2019).

54. Inoue, A. et al. Illuminating G-protein-coupling selectivity of GPCRs. Cell 177, 1933-1947.e1925 (2019)

55. Cherezov, V. Lipidic cubic phase technologies for membrane protein structural studies. Curr. Opin. Struct. Biol. 21, 559-566 (2011).

56. Caffrey, M. \& Cherezov, V. Crystallizing membrane proteins using lipidic mesophases. Nat. Protoc. 4, 706-731 (2009).

57. Li, X. et al. Crystal structure of the human cannabinoid receptor CB2. Cell 176, 459-467.e413 (2019).

58. Kabsch, W. XDS. Acta Crystallogr D Biol. Crystallogr 66, 125-132 (2010),

59. Adams, P. D. et al. PHENIX: a comprehensive Python-based system for macromolecular structure solution. Acta Crystallogr D Biol. Crystallogr 66, 213-221 (2010).

60. Emsley, P., Lohkamp, B., Scott, W. G. \& Cowtan, K. Features and development of Coot. Acta Crystallogr D Biol. Crystallogr 66, 486-501 (2010).

61. Schüttelkopf, A. W. \& van Aalten, D. M. PRODRG: a tool for high-throughput crystallography of protein-ligand complexes. Acta Crystallogr D Biol. Crystallogr 60, 1355-1363 (2004).

62. Zheng, S. Q. et al. MotionCor2: anisotropic correction of beam-induced motion for improved cryo-electron microscopy. Nat. Methods 14, 331-332 (2017).

63. Zhang, K. Gctf: real-time CTF determination and correction. J. Struct. Biol. 193, 1-12 (2016)

64. Scheres, S. H. RELION: implementation of a Bayesian approach to cryo-EM structure determination. J. Struct. Biol. 180, 519-530 (2012).
65. Heymann, J. B. Guidelines for using Bsoft for high resolution reconstruction and validation of biomolecular structures from electron micrographs. Protein Sci. 27, 159-171 (2018)

66. Emsley, P. \& Cowtan, K. Coot: model-building tools for molecular graphics. Acta Crystallogr D Biol. Crystallogr 60, 2126-2132 (2004).

67. Goddard, T. D. et al. UCSF ChimeraX: meeting modern challenges in visualization and analysis. Protein Sci. 27, 14-25 (2018).

68. Pettersen, E. F. et al. UCSF ChimeraX: structure visualization for researchers, educators, and developers. Protein Sci. 30, 70-82 (2021).

69. Kato, H. E. et al. Conformational transitions of a neurotensin receptor 1-G(i1) complex. Nature 572, 80-85 (2019).

\section{Acknowledgements}

This work was supported by Natural Science Foundation of China grant 31972916 to Z.S.; Ministry of Science and Technology of China grant 2019YFA0508800 (Z.S. and Y.Z.); Science and Technology department of Sichuan Province 2020YJ0208 (Z.S.); National Natural Science Foundation of China 81922071 (Y.Z.); Zhejiang Province Science Fund for Distinguished Young Scholars LR19H310001 (Y.Z.); Key R \& D Projects of Zhejiang Province 2021C03039 (Y.Z.); the National Natural Science Foundation of China Grant (32100959 to C.M.); Y.Z. is also supported by MOE Frontier Science Center for Brain Science \& Brain-Machine Integration, Zhejiang University. We thank Dr. Liang Ma for his help to synthesize compound 21 used in this study. We also thank staffs of the Center of Cryo-Electron Microscopy, Zhejiang University, BL18U beamline at National Center for Protein Sciences Shanghai (NCPSS) and BL41XU beamline of Spring-8. The diffraction data collection was performed at the BL41XU of Spring-8 with the approval of the Japan Synchrotron Radiation Research Institute (JASRI) (proposal number 2019B2705).

\section{Author contributions}

J.Q. and Y.C. designed the expression constructs, purified the ghrelin receptor complexes, and prepared the samples for data collection toward the structures. J.Q., C.M., and D-D.S. designed the Cryo-EM experiments and prepared the cryo-EM grids, collected cryo-EM images, and performed map calculations. Q.M. built and refined the cryo-EM structure. Y.C. and Z.X. developed the ghrelin receptor construct, purification, and crystallization. K.H. and Z.X. collected diffraction data. Z.X. solved and refined the crystal structures with help of J.Z. J.Q., S-Y.J., H.Z., and C.W. designed the cellular assays and analyzed results. Y.M., Y.Z., and Z.S. planned and coordinated the project, W.Y., Y.Z., and Z.S. supervised the overall project, and wrote the manuscript.

\section{Competing interests}

The authors declare no competing interests.

\section{Additional information}

Supplementary information The online version contains supplementary material available at https://doi.org/10.1038/s41467-022-27975-9.

Correspondence and requests for materials should be addressed to Yanbin Ma, Wei Yan, Yan Zhang or Zhenhua Shao.

Peer review information Nature Communications thanks Masayasu Kojima, Fei Xu and the other, anonymous, reviewer(s) for their contribution to the peer review of this work. Peer reviewer reports are available.

Reprints and permission information is available at http://www.nature.com/reprints

Publisher's note Springer Nature remains neutral with regard to jurisdictional claims in published maps and institutional affiliations.

Open Access This article is licensed under a Creative Commons Attribution 4.0 International License, which permits use, sharing, adaptation, distribution and reproduction in any medium or format, as long as you give appropriate credit to the original author(s) and the source, provide a link to the Creative Commons license, and indicate if changes were made. The images or other third party material in this article are included in the article's Creative Commons license, unless indicated otherwise in a credit line to the material. If material is not included in the article's Creative Commons license and your intended use is not permitted by statutory regulation or exceeds the permitted use, you will need to obtain permission directly from the copyright holder. To view a copy of this license, visit http://creativecommons.org/ licenses/by/4.0/

(c) The Author(s) 2022 